\title{
Nurturing Environmental Transformation and Scholastic Success in Northern Manitoba
}

\author{
Jeffray Roy Stepaniuk ${ }^{1}$ \\ ${ }^{1}$ Natural Resources Management Technology (NRMT) Program, University College of the North (UCN), The Pas, \\ Manitoba, Canada \\ Correspondence: Jeffray Stepaniuk, Natural Resources Management Technology Program, University College of \\ the North, The Pas, Manitoba, R9A 1M7, Canada. Tel: 1-204-627-8529. E-mail: jstepaniuk@ucn.ca
}

Received: February 2, 2021

Accepted: March 5, $2021 \quad$ Online Published: March 11, 2021

doi:10.5539/jsd.v14n2p122

URL: https://doi.org/10.5539/jsd.v14n2p122

\begin{abstract}
Effective non-traditional approaches to environmental lesson delivery and enrollee evaluation remain ephemeral in northern Manitoba as indicated by negative local attitudes towards imported and metropolitanized instruction (Martin, 2014; Mercredi, 2009). Current pandemic aside, and as increased attrition and abysmal failure rates have not changed in decades, there is relevance in exploring the experiential context and local implications of an inductive student model intended to improve remote environmental understanding and scholastic performance. To help prevent perpetuating a dis-order in which Indigenous expressions are neither recognized nor developed, learning experiences of University College of the North (UCN) students concerning regional freshwater availability and the calculation of stream flow were documented. Using componential analysis and participatory video as a mediating technology, allied empirical test scores and codified normative elements of self and environmental 'awareness' in traditional classrooms versus boreal settings were examined. Three exploratory factor axes explained more than $50 \%$ of the variance from an integrated but diverse set of 27 chosen variables. Titled axes declining in order of importance were Environmental Engagement, Scholastic Scoring and NonConventional Lesson Delivery. Seventy percent of unsolicited adult student responses suggest moralization and unique meta-ethical quale were undeniably and academically important. Empirical-'ized' findings advocate UCN must now ask which aspects of curriculum design, lesson delivery and enrollee assessment might result in greater scholastic success when nurturing personalized transformations in the milieu of ongoing threats to both freshwater sustainability and Cree safeguarding paradigms in northern Manitoba.
\end{abstract}

Keywords: adult education, curriculum design, engaged learning, environmental awareness, environmental transformation, freshwater sustainability, indigenous learning, participatory video, situated learning theory, University College of the North (UCN)

\section{Introduction}

\subsection{Obligatory Engagement}

Sustainability challenges related to monitoring freshwater in remote segments of northern Manitoba center on place-based awareness and technical aptitude. Repeatedly, these challenges are uncelebrated where Ininiwak and Indigenous communities often struggle to participate due to gaps in underlying knowledge required to comprehend scientific findings, rather than contribute geo-cultural nuance and abilities to help produce essential data. Fractious situations result in local mis-interpretations of applicable science and acceptability of practice where University College of the North (UCN) strives to codify what is regionally ethical and dialectically acceptable (Mercredi, 2009; Wilson, 2008). Accordingly, place-responsive discourse and lesson delivery must make every effort to understand how characteristics of remote adult learning relate to enrollee training and assessment. Despite expressions of local values being ubiquitous, eco-intelligent erudition lacks conventions for human-dimensions research ethnosemantically designed to explore normative constructs, inter-cultural group-mindedness and regional meta-physical 'gifts' in context.

In effect, this means overcoming similar training obstacles of geographic remoteness that Snowden (1983) implicated in eastern Canada's Fogo Islands including isolation, an agentic lack of confidence, and the conscientious use of nature. These edusemiotic connections bridging the gap between science, practical experience, transformation in habits and responsive obligatory engagement, have largely been ignored in Manitoba's North; 
for instance, the construction and promise of a participatory approach that welcomes purposeful learning, that recognizes vernacular expressions are necessary, and that considers the delivery of non-traditional teaching styles as valuable.

Since Dewey (1938), eight decades of research have focused on methods of erudition to influence habits, intentions and behaviors to produce results consistent with social values, yet incommunicable coaching and inconsistent assessment remain debatable. Regional scholars suggest germane psychometric approaches to environmental lesson delivery and early-stage evaluation remain inattentive (Mercredi, 2009; Wilson, 2008; Martin, 2014). From an institutional perspective, coherent curriculum delivery and program exit strategies can be demonstrably inconsistent in approach. Case in point, the UCN has offered Aboriginal and non-Aboriginal Natural Resources Management Technology (NRMT) programming simultaneously based on current political dialectics.

Regrettably, northern postsecondary decision-making and alliance with satellite First Nations communities has been challenging. More than twenty-years ago, Indian and Northern Affairs Canada (INAC, 1997) identified a number of obstacles to open collaboration. Persisting in these unforgiving terrains are fiscal inequity, cultural stigmata, indistinct academic authority and insufficient technological proficiencies. Humbly, the rate and pace of environmental change in Manitoba's north is rapid, while formal knowledge production is 'perceived' locally to lag in pragmatic utility undermining eco-intellect.

Postsecondary facilitating philosophies in particular, are repeatedly tested by place-based enrollee learning modality and 'geographically perceived' institutional responsibilities (Pryor et al., 2012). Unfortunately, remote STEM lesson approaches are alleged irrelevant indicated by high dropout rates, negative attitudes towards education, mis-specified sponsorships and a startling disinterest in fragile community existence. Despite an increased provincial recognition for the importance of freshwater sustainability and the fact Dene and First Nations cultures assert water must be revered by all (Michell, Tsannie \& Adam, 2018), only a small proportion of Manitoba's population (1.5\%) is watchfully examining freshwater-related topics (Manitoba Bureau of Statistics, 2016).

\subsection{Addressing the Notion of Failure}

Presumed stale with respect to "relational accountability" (Wilson, 2008, p. 123), imported didactic instruction in northern Manitoba does present legitimate strengths. Assets include solidifying foundations in reading, writing, document use and numeracy required for synergy in new skill development, knowledge acquisition and strongsense critical thinking (Adult Learning, Literacy and Essential Skills Program [ALLESP], 2016). Of concern nonetheless, are limitations and disconnect from a north-sensitive context when place-based education techniques are ignored. Recognizing the primacy of Indigenous inter-relations in this region consequently involves identifying a distinctive form of 'being' that does not easily condense to formal lesson delivery.

According to Lim and Chai (2008) and Diep. et al. (2019), on-line protracted conveyance and rote scholastic measure fail to capture representational portions of an isolated existence. The importance of emic curriculum design, micro-credentials and experiential hybrids must be realized if scholastic challenges and the notion of failure are to be effectively addressed (Manitoba Education Research Network [MERN], 2017). Topics in values assessment need attention as environmental decision and action are increasingly being challenged by shifting perceptions. A caring assessment and psychometric evaluation is necessary as imported processes are inadequate in these 'insulated' regions while globalization requires an obligation to becoming aware of environmentally wicked problems (Rittel \& Webber, 1973). Importantly, transformative paradigms of 'should' and 'ought to' must reach into the ecological dimensions of northern remote life. Consequently, offering moralized guidance about what might constitute ethically correct behaviors toward local environment and what kinds of actions are 'right or wrong' is the prescriptive element of this study's lesson delivery and evaluative rationale.

As global brevity pervades northern Manitoba, its effects amplify this research's context, as unblended deliveries are perceived bereft of regional substance (Wilson, 2008). This ontological suggestion is chronotopically (i.e., of time and place) imperative as the need to protect the nexus between boreal freshwater and remote denizen expression is indispensable. Defined as a situation in which 'urgent action is required to reduce, halt and avoid irreversible environmental damage', the Oxford Dictionary (2019) encapsulates this unrelenting doctrine declaring immediacy in appropriately facilitating new ecological understandings worldwide. Without listening to how situated northern learners are enlightened, the loss of moral impulse in lesson delivery and the preservation of the planet presents as regionally exacerbating.

\subsection{The Postulate of Adequacy}

To muddy undercurrents of eruditional disconnect, local Indigenous scholars indicate few opportunities for 
inclusion (Mercredi, 2010; Wilson, 2008). Native intelligentsia maintain local concern flows from different understandings of experience and traditional lifestyles where northerners detect unfamiliar themes in metropolitanized lesson transfer (UCN Elders Council, 2020). Culturally framed, regional andragogical belief is that Indigenous intergenerational views have lost the ability to remain relevant. Notions that streamside dialogues and 'extra-rational' knowledge help integrate social objectives, and that each is as vital as empirical evidence, seem untenable.

Presented textually, traditional cultural expressions are progressively integrated into new Euro-Canadian literacies (Atleo, 2008). Research growth appears to be intensifying due to groups of "scholars producing not only academic material, but feeding information into international policy" (Oakes, Muir \& Joseph, 2000, p. 12). However, as Bocking (2005) submits, millions of dollars are spent on ignored studies contributing little to no understanding of natural science nor blended ontologies. Widdowson and Howard (2009, p. 248) go so far as to profess the tendency of social scientists even "wanting to believe Traditional Knowledge has value, misappropriates funds towards resource-focused institutions" including the Natural Resources Institute (NRI) at the University of Manitoba, just 650 kilometres south of UCN. Ardently, local perspectives seem disappointingly incompatible with the requirements for accredited grade labelling and contemporary scholarship as remote learners continue to perform 'poorly' in northern Manitoba postsecondary classroom settings.

Nevertheless, collective environmental complexities confronting northern communities require an ever-greater amount of technical knowledge and skill. As such, there continues to be a great deal of thought regarding the provision of chronotopic culpability in environmental lesson design. Increasingly, alarmed educators believe it vital to focus on non-conventional lesson assessments because it is partially through teachings and spaces outside of educational institutions that student self-identities are shaped (Sandlin, Wright \& Clark, 2011). Mounting discourse suggests existing uni-dimensional didactic approaches are of little use if seeking to promote systematic distinctions between unjustified belief and opinion, and germane scholastic advance in 'boreal oriented' opportunities (Mertens, 2014; Arghode, Brieger \& Mclean, 2017).

Facilitators who emphasize social knowledge construction affirm these views (Yarbrough, 2018) as nothing so animates anecdotes between aspiration and achievement with dialogic audiences "as someone telling what they think or what they do - in their own words" (Zinsser, 2006, p. 81). Bandura (1977) and Vygotsky (1978) argued early that learning is inherent, socially embedded in particular settings and that what is true in one time and place may become false in broader constituency. Atleo (personal communication, 2019) advises 'information' and 'data' are only significant if integrated into the continuity of experience and the living. Admissibly, particular ideas become useful within a specific 'community of practice' and what counts as useful knowledge is determined in part by how well these ideas fit with accepted place-conscious credence (Lave \& Wenger, 1991).

Suitably, conceptualized place-sensitive modeling is acceptable if it makes vernacular sense to those considered. To convey a deep understanding of the way participants' reason, learning theory is presumed meaningful if educators use the correct methodologies, deliveries and technologies (Phare, 2009; Rasheed, Kamsin \& Abdullah, 2020). Smart (1976) aptly labeled this process the 'postulate of adequacy' asserting that if a scientific action were presented to an individual as curriculum, it must be understandable, translatable into action and comprehensible in terms of a common sense collaborative interpretation of everyday life via a repetitive process with an aim of approaching a targeted result. Awkwardly, the theoretical genesis for this research is the 'idea' that knowledge acquisition and skill assessment are classroom and on-line explicit.

\subsection{Perpetuating a Disorder}

Inarguably, the field of adult education has long relied on theories of learnedness grounded in oblique concepts of social and behavioral progress, but other than Bloom, little exists in the way of evaluative mixed-metric consideration of an accepted rubric to recognize extra-rational constructs. Missing from northern educational discourse and responsive local understanding is a focus on assessing the reality of meaning systems (i.e., beliefs, values, cultural sharing and emotions) including overt transformative reviews of extraordinary events signified by eureka, 'aha moments' and qualia. As a result, adults perceived in academic jeopardy tend to be scholastically vitiated by default metropolitanized lesson designs.

Continued absence of diversity in lesson transfer inundates remote Indigenous abilities, perpetuating a dis-order in which neither heuristic lore nor local 'scientific' aptitudes are recognized. What is needed to improve remote learning and teaching is to incorporate research into "circumstances that determine when narrower or broader contexts are required and when attention to narrower or broader skills are optimal for effective and efficient learning" (Anderson, Reder \& Simon, 1996, p. 10). Archetypally unimaginable, graduation is not compulsory for regional competency nor employability in this somewhat dejected northern region. Presumptive educational 
projections of every entry-level applicant 'walking the stage' ill-represents a percentage of the intention. Exploratory research targeting participant constructions of learning are necessary as a first step, to affirm the surprising degree to which these adults bring their novel dimensions to contemporary educational practice.

Interpretive methods used for creating sense of student experience and persistence that incorporate both scientific rigor and phenomenological sensitivity (i.e., meaning) are the markings of such ethnosemantic exploration. While Howley (2005) noted 'student first' perspectives can bridge emergent lesson design, UCN is uncalculatedly seeking to recover environmental traditions borrowed from surrounding communities in ways that are student responsive (UCN Academic Plan, 2020/2025). As such, academic achievement and consequent behavior are the analytical orientation in this investigative approach. Inconveniently, this dual premise is too often perceived imponderable and beyond the purview of existing lesson delivery. As a result, limited attention on establishing how student moralization might take place, and whether or not it is possible to assess, is marginalized.

Currently, strong debate at the UCN is how to acquire this tangible place-sensitive knowledge and assessment with participants and incorporate it in a respectful manner that is communicable and understandable to staff and students, while an Aboriginal President has been forcibly escorted from the property. Aboriginal academics with Ph.D.'s, decades of experience and the qualities needed in a modern post-secondary president are still in short supply. Dr. Denise Henning fit these criteria, and yet, was ousted for opposing a 'mandatory' Indigenous awareness program promoting what she was led to believe generated nothing but "white guilt" (Martin, 2014). If remote northern erudition and UCN are serious about envisioning ethical alumni, the potential for non-conventional lesson transfer and the development of place-based evaluative theory remain mis-specified.

\subsection{Model of Place - Participatory Video Rationale}

Although Glesne and Peshkin (1992) suggested research that examines 'your own backyard' is politically risky, Creswell (2007) posited that when it is important to study one's own organization, multiple strategies of data collection and validation help ensure the account is insightful and accurate. As such, remote institutional obligation must build and transform existing ethnomethodologies and use new technologies in transparent development designed to improve present condition. Instead of shunting remote students into disjointed academic thalwegs, UCN needs to arrive at a temporal solution where its learners play durable roles in northern societies beyond the $53^{\text {rd }}$ parallel. Subsequently, there is immediate relevance in exploring the implications of a student-generated learning model of place (Martin, 2014). Henceforward, this exploratory comparative case study probes empirical test status, normative epistemological vocabulary and axiological associations adopted by 97 reality-defining postsecondary enrollees with the intent to develop an interpretive approach for impassioned scholastic insight while documenting stream discharge calculation using participatory video (PV).

From the ethnosemantic shadow of Donald Snowden, 'film' is again emerging as one existing and ad-hoc andragogical approach as "videos containing the views, evaluations and descriptions of projects by the participants themselves are always the best and most transparent way of communicating" (Chris Lunch, personal communication, 2018). As an iterative process, PV has been documented to value cultural expression and traditional knowledge, build connections between communities and decision-makers, and enable participants to control decisions impacting their lives locally (Chowdhury, Hambly Odame \& Leeuwis, 2014). Used as a process, $\mathrm{PV}$ provides a forum for examination, bridging dialogic gaps to encompass agentic constructs of Indigenous storytelling and the unintended responses of those typically excluded. Thick digitally captured descriptions provide attending participants the opportunity to incorporate 'their' affective insight while the learning derived raises local 'awareness' of unexplored themes providing exciting opportunities for archived review and clarification.

From model inception to germane inclusion, a key aspect of using PV was the focus on local students as subjectmatter experts to confidently document the situation from their posture rather than researcher focus. It was believed this PV style of mass and individual exploration would generate valid heuristic ideas without imposing a prestructured research design. This integration of affective dimensions as informed by allied and unsolicited qualitative response offer unique and exhilarating dimensions to further assess lesson design, delivery and assessment at UCN.

Interestingly, Lunch (2008) proposed "participatory video, with its ability to convey a rich picture, could help [other methods] go even further making video more accessible to all kinds of audiences, and to all parts of the communities, including children, the elderly and the illiterate" (p. 30). As such, PV was perceived highly relevant as a regionally applicable technology for UCN's relatively small number of beneficiaries; a customized 'process' in a remote northern context to which conventional lesson delivery and evaluative techniques were supplying insufficient feedback (UCN Animal Care Committee [ACC], 2020). Subsequent considerations regarding this 'non-leading' ethnomethodology were clarified according to the institution's Governing, Learning and Elders' tri- 
council directives and the University of Manitoba Joint Faculty Research Ethics Board.

A definite methodological goal was to promote the investigative dexterity of PV suggesting how qualitativeoriented content can serve quantitatively. Class and stream level video-ethnoanalysis accordingly would provide descriptive and theoretical insight into didactic delivery, place-sensitive alteration in lesson design, and the perceived need for improved evaluative practice. Investigative emphasis was on examining encoded normative elements of respondent self-awareness and environmental decency alongside allied quantitative test scores previously dissected (Stepaniuk, 2019). As boreal Indigenous students are intricately linked to their lotic surroundings, remote ethnographic expression would offer exciting mixed data assemblages concerning community and freshwater sustainability while sensitizing UCN to vital challenges in video interviewing.

\subsection{Objectives}

As a principal research purpose was to describe, better understand and enhance remote postsecondary evaluation by providing learning strategies to improve student understanding in ways that may be used by UCN in northern Manitoba, the methodological question lingering was: could PV, used as a process, formalize its obvious potential as a psychodynamic monitoring and archival tool while developing an added scholastic and quantifiable element to an otherwise highly-qualitative commodity? Consistent with Zinsser (2006), local concern was discerning how these isolated and contemporary learners "construe their world of experience from the way they talk about it" ( $\mathrm{p}$. 29).

With a constructive, practice-improving mixed-focus in mind, specific research objectives were to: 1) characterize student experience and scholastic ability connecting theory to mixed and applied learnings; 2) determine whether scholastic differences in student performance were the result of lesson type rather than a conventionally defined geographic or culturally 'perceived' shortcoming; and 3) define the degree to which alternative place-sensitive lessons promote watershed awareness, proximal belief, operant behavior and perhaps a sense of agentic advocacy regarding ecological training and freshwater sustainability.

As it is widely acknowledged that an increasingly informed and environmentally sensitive public counts far more towards environmental protection than any judicial reform (Law Reform Commission of Canada, 2016), a final intent was to analyze whether place-based ecological morality and behavioral substance were denied 'academic meaning' and a tendency to stimulate corresponding attitude-attributions in motivated cognition and ecologic conscience. Could in-situ generated insight and documenting PV provide evaluative measure into a conceptual model as a reliable and valid instrument of considerable utility in local research for isolated graduates in the midst of forthcoming environmentally wicked circumstances? As these 97 remote student identities offered encouraging place-sensitive repositories of ecological decency, denying investigation of the possibilities for northern agentic guardianship could not be ignored.

\section{Methods - Study Design}

This postscript level of mixed ethno-analysis goes beyond quantitative data collection and pre-analyzed scholastic ranking of UCN student test scores in Stepaniuk (2019). Five additional method phases integrate preceding appraisal with accompanying and quantified affective beliefs (Figure 1). Integrated analysis includes: 1) PHASE 3 - student-directed participatory video (PV) documenting both didactic and stream-level lesson delivery experiences; 2) PHASE 5 - digital video capture, edit and pre-sorting of post-activity open-ended non-Likert student interview response; 3) PHASE 6 - open, ethnosemantic (i.e., construct through structuralist) axial and selective coding of unsolicited qualitative candidate offerings; 4) PHASE 7 - conceptualized integration of mixed theme discovery with pre-analyzed test score rankings; and 5) PHASE 8 - exploratory factor analysis (EFA) of mixed self and empiricalized themes $(\mathrm{n}=27)$ culminating in a northern place-sensitive theory (Figure 3$)$. 


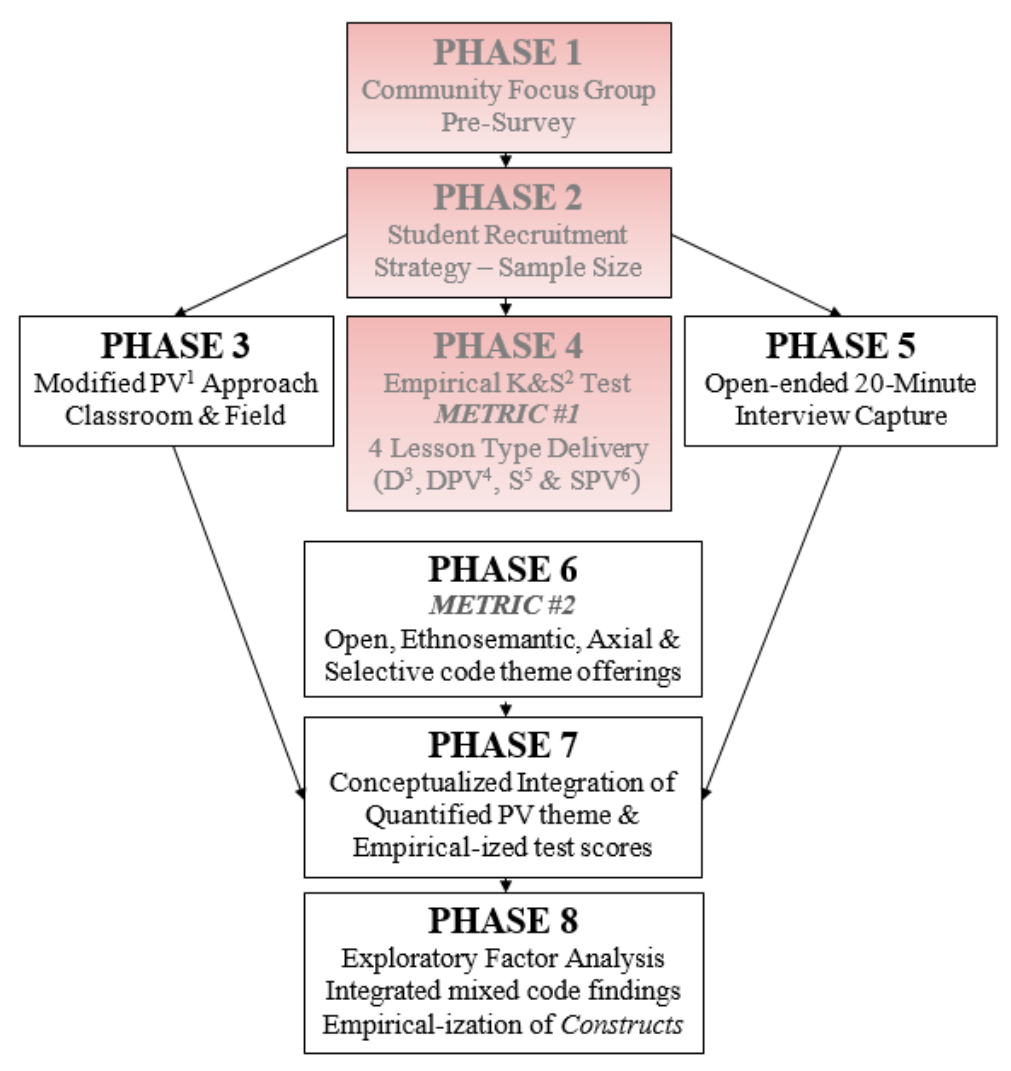

Figure 1. Subdivision of research design sequence between eight component phases of integrated analysis. Highlighted PHASES 3, 5, 6, $7 \& 8$ form the ethnosemantic and factor analysis basis of allied mixed data examination.

$1=$ Participatory Video; ${ }^{2}=$ Knowledge \& Skills; ${ }^{3}=$ Didactic Lesson; ${ }^{4}=$ Didactic plus Participatory Video Lesson; ${ }^{5}=$ Situated Lesson; ${ }^{6}=$ Situated plus Participatory Video Lesson

\subsection{PHASE 1 - Focus Group Survey - Searching Motives for Methodological Practice}

Regional pre-study community focus group sampling was designed around Husserl's (2012) concept of 'bracketing' social assumptions and a Colaizzi (1978) and Moustakas (1994) phenomenological approach in which I set aside my beliefs to welcome new perspectives when exploring this northern Manitoba phenomenon. Pre-study community focus provided a way to identify concerns, local stressors and research direction (Banyard \& GrahamBermann, 1993). I used a maximum variation sampling philosophy that consisted of determining criteria that would differentiate student constituent offerings (Creswell, 2007). Following Fetterman (1998), I included outlying individuals via a 'big net approach' identifying those responses within a larger continuum of replies I would use to ground mixed data.

Community focus data consisted of 20 hours of video documenting outcomes of eight community groupings (i.e., Sapataweyak, The Pas-Opaskwayak, Thompson, Norway House-Kinosawi Sipi, Grand Rapids-Misipawistik, Easterville-Chemawawin, Snow Lake and Gillam-Makaso Sakikan). Open-ended questions probed participant priorities, local challenges, fondest memories, regional frustrations and place-sensitive personal experiences. Data collection rested on non-ordered group recommendations derived from the ideas of Lovett (1983) who declared, "people need to think about the nature of society in which they live" (p. 5). Based on this intent, these eight agentic gatherings produced heuristic themes around watershed awareness, flooding, river diversion, community displacement, hydroelectric power, high voltage direct current right-of-ways, culture, education, local technical inability and the availability of freshwater.

Audio-visual information was viewed several times to obtain insights into local concerns. Decisions regarding potential lesson transfer and assessment arose from these eight community gatherings and UCN Elder suggestions which provided local Cree expression informing decisions regarding a northern remote context, who should be 
sampled, and how research should progress with prospective students enrolling the coming September.

\subsection{PHASE 2 - Student Recruitment Strategy}

During the first week of regular classes, a 60-minute period disseminated introductory information to 348 entrylevel postsecondary students. In order to develop theory and a prospective model originating from focus group (i.e., PHASE 1) and core community concern, a student sample was solicited. Participants were recruited through opportunistic sampling of seven disciplines (i.e., Nursing, Dental Assisting, Early Childhood Education, Law Enforcement, Business, Kenanow Education and Natural Resources Management Technology [NRMT]). Rationale for acquiring a heterogeneous student sample necessitated conditions under which a lesson delivery model would be valid. Student sampling strategy benefited from conceptualizations by Marshall and Rossman (2014) who suggest sampling aspects of the event, the setting and the participants.

Data was collected in terms of all three levels of sampling: 1) didactic lecture in the classroom and situated demonstration at the 'event' [or stream site level] - evaluation of scholastic knowledge and skill acquisition; 2) at the 'setting' [or process level] - in-field observation and PV examination of didactic and situated student group stream calculation experience; and 3) at the 'participant' level - 97 chronicled qualitatively-coded unsolicited open-ended student interviews. In accordance with UCN Elders and regional community focus-group submission (PHASE 1), students 'outside' NRMT were included in order to represent diverse regional perspectives.

Most important, UCN students would be adults who all experienced the learning phenomenon and who would all ideally articulate their lived experiences through PV and post-exercise interview. Creswell (2007) advocates focus must be on emergent statements, recognizing all candidates (related and otherwise) have stories to tell. Field-level data collection and situated engagement in a wadeable stream were launched some time following where 97 of the 348 enrollees assembled into groups of three to five. All student groups were exposed to either didactic or situated explanations of stream flow determination.

Stream flow or 'discharge' is defined as the volume of water flowing through a given cross-section of a stream channel during a given period of time (expressed in cubic meters per second) requiring several measurements of depth and velocity to yield an average calculation. Velocity calculations were obtained using the Price No. 622 Type AA Current Meter and each participant used a Sony Digital Camcorder (DSR-PD170) to video-document their experience. Upon exercise completion, each student was asked to address an on-site questionnaire capturing three-to-five immediate impressions of their experience which were intended to encourage feedback and retention for post-activity interviews reducing bias that would otherwise favor participants with greater writing facility (Plate $1)$.



Plate 1. Participating student addressing on-site questionnaire capturing immediate impressions of their situated stream learning experience. 


\subsection{PHASE 3 - Modified Participatory Video Approach (Didactic and Riparian)}

Classroom and field video documentation involved an interpretive approach meant to observe student action where each informant would experience a stream discharge calculation event and attempt to make sense of the in-stream phenomenon as related to their experience regarding exposure to either a didactic or situated lesson transfer using the supplemental participatory video (PV) technique. On and off site, PV was to provide students with an opportunity to reflect on their training experience and to share their insights regarding learning 'in-the-classroom' and 'in-the-river'. Chase (as cited in Denzin \& Lincoln, 2005) suggests such access to ethnomethodological performance situates individual stories within respondent experience.

In contrast to Johnston (2002), I used a modified PV technique allowing each UCN student to comment on individual and collective perspectives using their own words to explicate exercise-related questions, confusions and 'awareness' generated that were later open-coded without group edit. Based on real or perceived status, Johnston (2002) reported participant discomfort in multiple-evaluation group feedback situations. The fact Johnston's participants were compelled to lobby on behalf of their own observations, be too generous to colleagues, and experience tacit pressure to support comments of the researcher or dominant personalities, I used a 'modified' single-frequency PV procedure to chronicle streamside perspectives and post-interview offerings in this northern Manitoba study.

\subsection{PHASE 4 - Empirical Knowledge and Skills Acquisition Test (Stepaniuk, 2019)}

Upon completion of the stream activity, a 22-question 57-mark knowledge and skills acquisition test was administered to each student. For purposes of research integrity, specific test questions were not provided prior assessment. Pre-prototype questions considered for skill acquisition were verbalized only when participants were first recruited. The time provided to complete the test spanned 1-2 hours. Test questions were separated into those: 1) necessary for understanding $\{12$ questions / 23 marks $\}$, and those 2) mandatory for procedure $\{10$ questions / 34 marks $\}$. Empirical outcomes are detailed in Stepaniuk (2019).

\subsection{PHASE 5 - Open-Ended Interviews and Unsolicited Candidate Response}

To study as many individuals as possible and collect extensive detail about each, the intent was not to generalize information but to extract specifics (Pinnegar \& Daynes, 2006). Consequently, it was important to elicit specific personal meaning of the in-stream phenomenon from all UCN students (i.e., didactic and situated) who would experience it. To acquire ethnosemantic meaning and supplement classroom and in-stream PV documentation, I conducted unstructured follow-up interviews with each of the 97 UCN students. To learn with these participants from seven different programs, each having different levels of involvement in the natural environment (including individuals with whom the environmental movement was peripheral to their lives - i.e., Business Administration), interview procedures were open-ended in nature.

Interviews consisted of video-documenting each student, gathering thick data through the collection of individual experiences and ordering their meaning. I used a pre-designed questioning format and Final Cut Pro to record and assemble all interview responses. To better obtain a wide diversity of experiences and thoughts, each student was asked to respond to the following two open-ended questions:

1) How did participating in this exercise affect you - can you provide an example using some aspect of how the exercise or process unfolded?

and

2) Were you aware of any consequences (i.e., benefits or dis-benefits) of your participation - what was central to the exercise or process for you and why?

Greater depth and diversity in questioning was achieved by asking two additional open-ended questions on the back end of the interview, inviting interviewees to focus their attention on generating unsolicited input that would lead to greater textural description of their in-stream experience and ultimately provide understanding of streamlevel calculation challenges, if any:

1) Is there anything else that you can tell me to help 'me' understand 'your' experience? and

2) Is there anything you would like to ask regarding the project and your participation in this experience? 
Student interviews each lasted 20-30 minutes and proceeded until no new themes emerged. In total, involvement in this project required each student commit 12 hours for didactic-lecture and 11 hours for situated exercise; an accumulative 1119-hour student offering.

\subsection{PHASE 6-Operationalization - Open, Axial and Selective Coding}

In order to complete the stream discharge calculation task on-site, each UCN student was asked to reflect upon the exercise and its delivery in order to provide their skill-set insight into stream channel - area, velocity and volume calculations. The situated plus PV method, posited in this aspect, would speak to all students equally (i.e., culturally or perhaps using no language whatsoever) when dealing with challenges of direct relevance to northern Manitoba freshwater sustainability at the community level. At this pre-conceptualization stage, I first posited mixing previously collected test scores with the idea of 'empiricalizing' qualitative construct themes attained 'in-field' and during interviews (Figure 2).

In accordance with early work by Bateson and Mead (1942), UCN video accounts would permit repeated and refocused opportunities to define the idea student experiences of the 'seen world' were contextually codable. Giving literal insight for how to incorporate these accounts into scholastic notions of code alignment, Sharrock and Anderson's (1979) ensuing research, four decades later, suggested a contemporary theoretic reasoning that was both operationally and methodologically 'practical'. Their findings, four decades ago, indicated experiential and invisible extra-rational data 'could be' transformed from a qualitative visual platform to coded expressions of these northern students' instream phenomena 'quantitatively'. Participatory video in effect allowing UCN assessors to 'see' in order to make unseen subjective expressions empirically accessible. It was this mental processing that would eventually enable identification of antecedent connections to better assess student learning modality and codify operant behavior.

\section{Instrumentation}

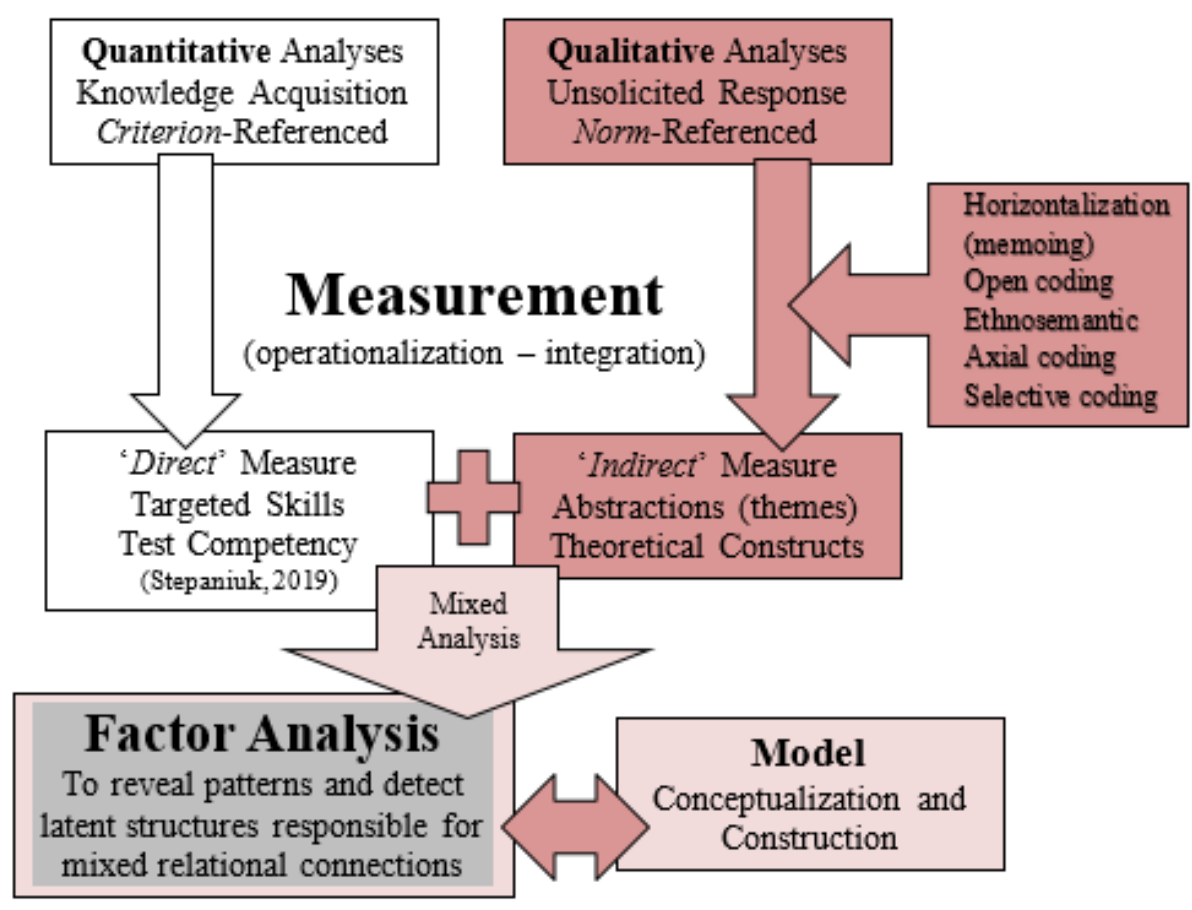

Figure 2. Mixed data conceptualization and construction of an emergent place-sensitive theoretical model.

Referred to by Moustakas (1994) as 'horizontalization', analysis of student interviews consisted of: 1) viewing the footage several times to obtain an overall understanding; 2) identifying significant statements that pertained directly to the experience providing an understanding of how each student experienced the video and stream phenomenon; and 3) formulating meanings to cluster statements into constructs common to all participating 
student video-interviews. An initial open coding process described by Strauss and Corbin (1990) fractured unsolicited student responses, allowing identification of broad-spectrum categories and any theoretical dimensions for consideration.

Successively spanning a 'content' through 'structuralist' array of considerations searching for commonality in conscious experience and viewpoint, the idea was to determine attributes and response-clusters from unsolicited statements while considering indicators that would signify normatively surfacing codes, related themes and emerging constructs (Firth, 1973). By definition, 'content analysis' for Berelson (1952, p. 18) delineated a research technique for the systematic and quantitative description of the 'manifest' content of communication, where qualitative dimensions could be quantified by assigning numerical values to theme frequencies. Similarly and with these northern UCN respondent excerpts, audiovisual objectivity resided in devising clearly defined categories applied to digitally captured material in accordance with explicitly formulated rules. Unfortunately, as code labelling progressed and 'content analysis' was recognized as rudimentary, a more analytical apparatus to investigate UCN student expressions became mandatory.

Approaching Williamson's (1978) 'structuralist' philosophy, analytical and axiological methods evolved to reside in "what [could] be seen" (p. 11), as maintaining visual imagery in valid category assemblages needed to consist of not only the 'content' (or words), but the meaning ascribed to the words. To appropriate correlative relationships between test scores and 'signifying' testimonials, genuine 'meaning' needed to result from a logic addressing a northern agentic 'referent system'. Accordingly, the ethnosemantic core of this analysis involved delineating observational and behaviorally significant clusters and then spelling out label relations using a structuralist's slant.

To operationalize pre-model strategy, I targeted emerging themes such that each could be identified and intuitively related. Observable empirical indicators would be the end products of this process, becoming items that permitted declarative statements about emerging theme-clusters and an evolving place-responsive model framework. Open and ethnosemantic coding essentially delineated what participants had in common as they calculated river discharge from protracted lecture or situated 'in-stream' lesson delivery. From this procedural process, normative categories emerged and were assigned labels. Axial coding put these response clusters "back together in new ways by making connections between a category and its subcategories" (Strauss \& Corbin, 1990, p. 97). Criteria for status included: 1) the frequency of a theme's occurrence in student response; 2) its inclusiveness and ease with which the statement related to other themes; and 3) the clarity of each statement's implication for a northern inductive theory. The final step was selective coding, an integrative process selecting core themes, systematically relating each while addressing any that needed refinement.

\subsection{PHASE 7 - Conceptualization - Discovery and Integration of Quantified Themes}

Model design was an inductive process working through multiple levels of abstraction, forming categories but then reconfiguring clustered statements into new and revised taxonomies. Cortazzi (1993) suggests this 'restorying' process links ideas to a chronology of participant experience. Model design emerged from memoing throughout horizontalization. The result was a substantive-level grounded theory specific to a local challenge and a northern student population; a place-sensitive theory that could be triangulated through a structuralist format for empirical verification (Figure 3).

In operational and conceptual summary, as some constructs I measured were intangible (i.e., conscious subjective experiences or qualia), conceptualization helped to describe and formulate an iterative method for examining arising overt student behavior, meta-ethical constructs and scholastic inference regarding environmental advocacy. This pre-through-post-method process provided the necessary abstract understandings, statistical theory assurances and hypotheses for surfacing result subtleties.

Amalgamation of quantitative test score findings (Stepaniuk, 2019), situated PV and unsolicited interview code themes provided a unique measure of assessment and verification rather than drawing solely from academic test scores or subjective video-recorded perceptions. Accepting this blended assessment design and procedural outlook, classroom and outdoor assessments were expected to promote a mixed scholastic and ethnosemantic blend as a reflection of an analytical formation. 


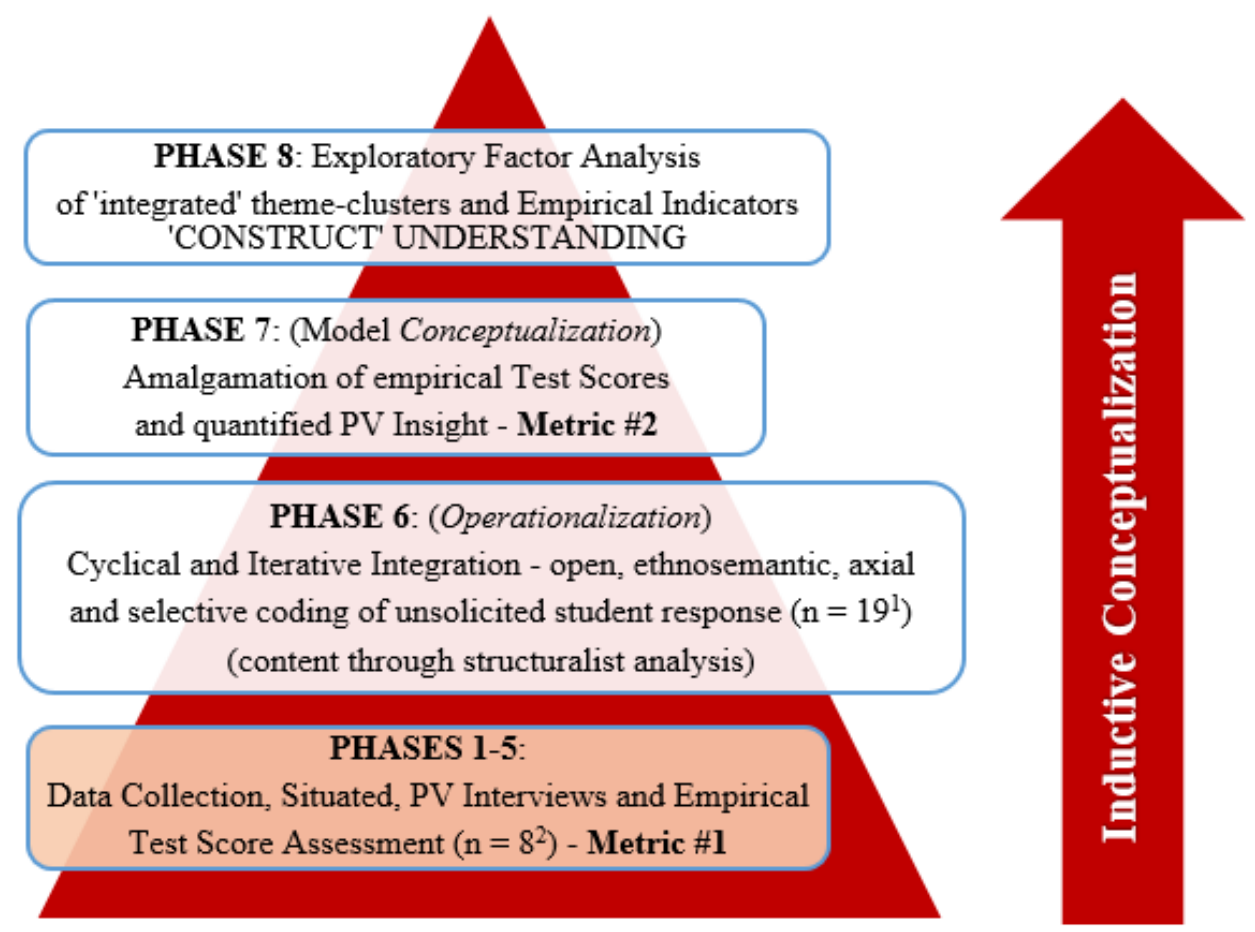

Figure 3. Integration of qualitative findings (Phases 6,7 and 8) following data collection and empirical test score assessments.

$1=19$ qualitative variables; and ${ }^{2}=8$ quantitative variables used in Exploratory Factor Analysis.

\subsection{PHASE 8 - Factor Analysis and Variable Integration}

In methodological summary, student respondents were first recruited, coached on equipment use, facilitated in didactic or situated lesson delivery, provided the opportunity to evaluate their own field-based perspectives, empirically tested, and afterwards express their unsolicited learning experiences in non-Likert designed interview sessions (PHASES 1-5). Since a large number of 'mixed' test scores and student video statements were considered (PHASES 6-7), it was decided early that exploratory factor analysis (EFA - PHASE 8) would offer a fuller explanation of dependent variable codes, reducing selected theme response to a smaller number of factors. To this end, EFA revealed underlying patterns detecting hidden constructs responsible for observed relational connection to mixed academic and affective 'score'. With a minimally preconceived structure on model development, I selected eight quantitative variables from pre-analyzed scholastic examination and 19 surfacing qualitative themes excavated from each of the four different lesson types (Table 1). 
Table 1. Selected independent quantitative and qualitative variables for EFA variable condensation.

\begin{tabular}{|c|c|}
\hline Quantitative Variables & Qualitative Variables \\
\hline $\begin{array}{l}\text { Programs ( } \mathrm{n}=7 \text { : NRMT; nursing; early childhood } \\
\text { education; law enforcement; business; dental } \\
\text { assisting; education) }\end{array}$ & Learning ( $\mathrm{n}=2$ : Situated or Didactic) \\
\hline $\begin{array}{l}\text { Lesson Types ( } \mathrm{n}=4 \text {; didactic; } \mathrm{DPV}^{2} \text {; situated; } \\
\mathrm{SPV}^{3} \text { ) }\end{array}$ & Collaboration $(\mathrm{n}=2$ : Yes; No) \\
\hline $\begin{array}{l}\text { Culture ( } \mathrm{n}=2 \text { : Aboriginal; Non-Aboriginal }- \text { self } \\
\text { declaration) }\end{array}$ & 'awareness' ( $\mathrm{n}=3$ : self; environment; exercise) \\
\hline Gender $(\mathrm{n}=2 \text { : male; female })^{1}$ & $\begin{array}{l}\text { Quale, eureka, aha moment, conscious subjective expression }(\mathrm{n}=2 \text { : } \\
\text { Yes; No) }\end{array}$ \\
\hline $\begin{array}{l}\text { Question Type ( } \mathrm{n}=5 \text { : multiple choice; sentence } \\
\text { completion; bullet answer; long answer; } \\
\text { calculation) }\end{array}$ & $\begin{array}{l}\text { Knowledge acquisition }(\mathrm{n}=5 \text { : } \underline{\text { Sub-codes }}=\mathrm{New} \text { experience and } \mathrm{PV} \text {; } \\
\text { knowledge sharing; educational development; social responsibility; } \\
\text { environmental knowledge) }\end{array}$ \\
\hline Test Evaluation $\left(n=3\right.$ : Total score; $\mathrm{NFU}^{4} ; \mathrm{MFP}^{5}$ ) & $\begin{array}{l}\text { Skills acquisition ( } \mathrm{n}=3 \text { : } \underline{\text { Sub-codes }}=\text { skill development; personal } \\
\text { development; improved learning strategy) }\end{array}$ \\
\hline & Changed Behavior ( $\mathrm{n}=2$ : Yes; No) \\
\hline Total Variables $=8$ & Total Variables $=19$ \\
\hline \multicolumn{2}{|c|}{ Grand Total Variables $=27$} \\
\hline
\end{tabular}

Selected predictor variables were perceived especially appealing to map new domains suited to this northern quest for an inductive educational theory regarding scholastic student ability combined with ethical place-sensitive operant behavior - each with high margins of error (Cody \& Smith, 2005). Moreover, EFA would indicate whether several allied measures used to assess learning gains could conceptually be thrown together as a single kind of assessment, or whether two or more distinct and independent kinds of learning were taking place. It was unacceptable to believe poor test scores and grade-based ranking (i.e., GPA) outcome would be influenced solely by a northern living culture. In short, the perceived benefit of using an ethnosemantic and EFA approach was to infer into a hidden set of constructs, these fewer in number than the original group $(\mathrm{n}=27)$ of independent predictor variables chosen. A resulting four-platform model of the main findings provided by this analysis frames the results with respect to the basic research questions set out using assessed scholastics, behavior and the need to nurture new ethical values and emotional connectivity.

Following selection of a skill-relevant combination of empirical and quantified-qualitative unsolicited response items, mixed data were evaluated using EFA several times before arriving at a chosen solution. Procedurally, SPSS was directed to suppress items that had loadings less than 0.3 or $9 \%$ (Comrey \& Lee, 1992).

\section{Results}

\subsection{Conceptualization, Definition and Model Development}

Digital recording by the students themselves proved particularly attractive when addressing conceptualizations of this ethnographic activity. Not only did this visual imagery and modified PV technique provide descriptive 'allied' analyses of UCN student attitudes and behaviors, it was instrumental in exploring theorized factor-associations with previously investigated test scores to provide penetrating results (see Stepaniuk, 2019).

Originating from classroom and instream lesson transfers, mixed findings indicated experiential opportunity encouraged students to film and speak for themselves. In turn, testimonials provided a naturalistic base for unbiased coding and a place-based model conceptualization. Appreciable in-situ videoing likewise played an accompanying role in encouraging responsive conduct change perceived 'healthy' for individual student wellbeing. Findings indicated a propensity for ecological guardianship and stimulated personal 'awareness' (Plate 2). 
According to O'Sullivan, Morrell and O'Connor (2002, p. xxvii) we learn in ways that change us and give us vision, compassion and strength to work for personal and social change.

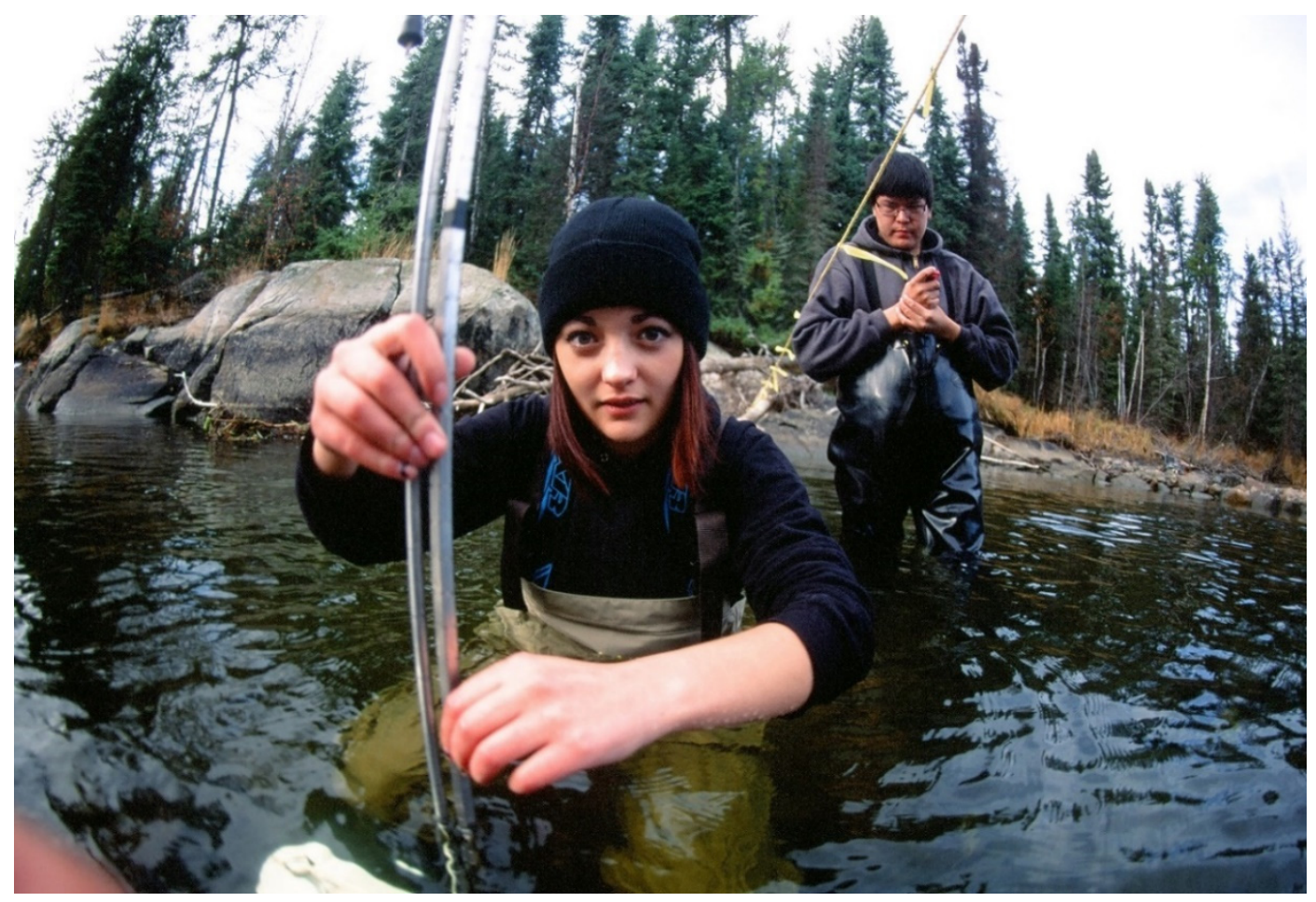

Plate 2. Student group preparing cross-section for stream velocity calculations.

Defined here as the study of methods used for making sense of everyday experience, digital ethnomethodology offered a framework for systematically examining each UCN student's willingness to execute a 'value choice' while participating instream. For instance,

"It [the exercise] taught me a lot about teamwork. I am usually a do-your-own-thing-kind-ofperson. I like doing things by myself. I don't really like depending on people for help or for other things because I get disappointed in them, but this brought my law enforcement class together. It taught us to get to know each other a little bit better because we only had been in school for the past four weeks and after this 'thing'we kinda bonded which was a good thing for my class and myself. I actually had fun doing something with people who I didn't even know. It's a really bonding experience and I really felt that when we did it."

Providing effective forethought on a taxonomy applicable to a northern conceptualized model, exploratory factor analysis (EFA) was crucial in revealing exciting correlations among learning patterns based on mixed quantitative test scores and quantified affective data from digitally-captured responses to yield a three-factor foci, explaining $50 \%$ of the variance from an original set of 27 selected variables (Table 2). Three dominant axes of variation identified through a structuralist philosophy in declining order of importance included: 1) Environmental Engagement, 2) Scholastic Scoring and 3) Non-Conventional Lesson Delivery.

Accounting for $25 \%$ of the total sample variance was 'Environmental Engagement' (Factor 1) or learning in ways meaningful within these northern students' life-world. This first construct and titled axis was designated by six large positive sub-loadings comprised of statements that referenced: 1) an 'awareness' of the environment $\left\{0.86^{9}\right\}$; 2) social responsibility $\left\{0.69^{9}\right\}$; 3) environmental knowledge $\left\{0.67^{9}\right\}$; 4) an 'awareness' of self $\left\{0.63^{9}\right\}$; 5) personal development $\left\{0.57^{9}\right\}$; and 6) knowledge-sharing in the community $\left\{0.48^{9}\right\}$ (Table 2$)^{9}$. The first thing to note is factor loadings related to mixed 'scholastic' ability were absent and empirical test scores alone did not present as Factor 1. The dominant axis rather, was 'situatedness' or Environmental Engagement. Although Scholastic Scoring (Factor 2) was indeed related, this axis accounted for a less dominant domain in signifying northern student 'ability'. 
Table 2. Three dominant factors underlying variability using mixed data.

\begin{tabular}{|c|c|c|c|c|}
\hline $\begin{array}{l}\text { Factor Number and Latent Inductive 'Construct' } \\
\text { Label }\end{array}$ & $\begin{array}{l}\text { Variable } \\
\text { Type }\end{array}$ & Variance & $\begin{array}{l}\text { Factor Loadings } \\
(\%)\end{array}$ & $\begin{array}{l}\text { Mean Scores } \\
\text { (SE) }\end{array}$ \\
\hline 1 - Environmental Engagement & & $25 \%$ & & \\
\hline 'awareness' of Environment (Aw) ${ }^{1}$ & Categorical & & $0.86^{9}(74)^{10}$ & $0.42(0.05)$ \\
\hline Social Responsibility (KA) ${ }^{2}$ & Categorical & & $0.69^{9}(48)^{10}$ & $0.24(0.04)$ \\
\hline Environmental Knowledge (KA) ${ }^{2}$ & Categorical & & $0.67^{9}(45)^{10}$ & $0.34(0.05)$ \\
\hline 'awareness' of Self (quale) (Aw) ${ }^{1}$ & Categorical & & $0.63^{9}(40)^{10}$ & $0.61(0.05)$ \\
\hline Personal Development (SA) ${ }^{3}$ & Categorical & & $0.57^{9}(35)^{10}$ & $0.27(0.04)$ \\
\hline Knowledge Sharing $(\mathrm{KA})^{2}$ & Categorical & & $0.48^{9}(23)^{10}$ & $0.14(0.04)$ \\
\hline 2-Scholastic Scoring & & $17 \%$ & & \\
\hline Calculation Question $(\mathrm{CA})^{4}$ & Continuous & & $0.83^{9}(69)^{10}$ & $3.40(0.32)$ \\
\hline Sentence Completion (SC) ${ }^{5}$ & Continuous & & $0.83^{9}(69)^{10}$ & $7.41(0.34)$ \\
\hline Long Answer Reply (LA) ${ }^{6}$ & Continuous & & $0.73^{9}(53)^{10}$ & $4.56(0.30)$ \\
\hline Total Test Score (TS) ${ }^{7}$ & Continuous & & $0.65^{9}(42)^{10}$ & $29.5(1.39)$ \\
\hline Multiple Choice Reply (MC) ${ }^{8}$ & Continuous & & $0.58^{9}(34)^{10}$ & $4.13(0.18)$ \\
\hline 3 - Non-Conventional Lesson Delivery & & $9 \%$ & & \\
\hline New Experience and $\mathrm{PV}^{11}(\mathrm{KA})^{2}$ & Categorical & & $0.68^{9}(47)^{10}$ & $0.27(0.04)$ \\
\hline Educational Development (KA) ${ }^{2}$ & Categorical & & $0.62^{9}(40)^{10}$ & $0.18(0.04)$ \\
\hline 'awareness' of Exercise (Aw) ${ }^{1}$ & Categorical & & $0.49^{9}(24)^{10}$ & $0.32(0.05)$ \\
\hline
\end{tabular}

${ }^{1} \mathrm{Aw}=$ situated 'a wareness' codes $(\mathrm{n}=3) ;{ }^{2} \mathrm{KA}=$ knowledge acquisition codes $(\mathrm{n}=5) ;{ }^{3} \mathrm{SA}=$ skill acquisition codes $(\mathrm{n}=3) ;{ }^{4} \mathrm{CA}=$ calculation question abbreviation; ${ }^{5} \mathrm{SC}=$ sentence completion abbreviation; ${ }^{6} \mathrm{LA}=$ long answer abbreviation; ${ }^{7} \mathrm{TS}=$ total score abbreviation; ${ }^{8} \mathrm{MC}=$ multiple choice abbreviation; ${ }^{9}$ Eigenvalue calculation was achieved by directing SPSS to suppress items loading less than 0.3 (or 9\%) following Comrey \& Lee (1992); ${ }^{10}$ Squared loadings in brackets show eigenvalue correlation strengths in percent; ${ }^{11} \mathrm{PV}=$ Participatory Video. Shading indicates non-scholastic variables typically unassessed.

Interestingly, participating enrollees demonstrating a willingness to process local experience and recognize new environmental insights, proclaimed, "I now have a realization that resources are abused and it is frightening to $m e$ " and "I have an awakening regarding my attention, caring and concern for the environment". Other Factor 1 supporting statements included: "I could be a little more honest with myself about how I really do feel and what I say as it is ok not to be easy going and to maybe embrace the assertive side of myself. Maybe it is a mask that I am wearing that I need to get rid of"; "I've never experienced anything like this before"; "I've developed an improved ability to network with like-minded people" and "others were really excited when I told them what I was doing". These typically unassessed beliefs, attitudes and sentiments ... expressed while sharing a hot tea in situ ... no doubt encourage principled social responsibilities for longstanding community-based erudition (Plate 3). 


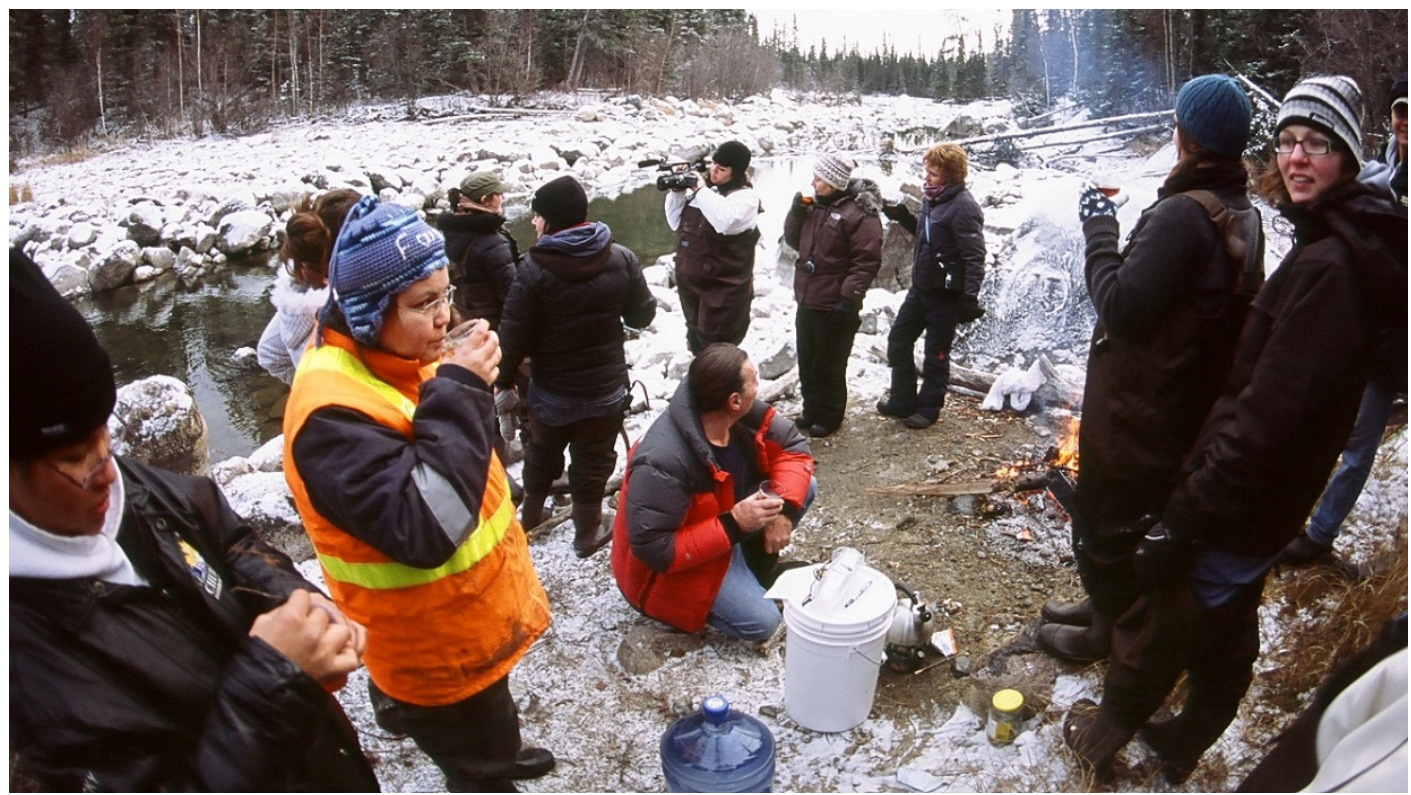

Plate 3. A streamside participatory video gathering of eclectic information on the meaning-making intricacies of each northern participant.

The second labeled axis was 'Scholastic Scoring' (Factor 2). This factor derivative was expected and interpreted as a rote academic dimension indicating little besides empirical test performance. Five factor attributes related to test scoring were: 1 ) calculation type questions $\left\{0.83^{9}\right\} ; 2$ ) sentence completion questions $\left.\left\{0.83^{9}\right\} ; 3\right)$ long answer questions $\left\{0.73^{9}\right\}$; 4) multiple choice $\left\{0.65^{9}\right\}$; and 5) Total Test Score $\left\{0.58^{9}\right\}$ (Table 2) ${ }^{9}$. Variance explained by this second exploratory factor analysis (EFA) plane accounted for $17 \%$ of the detected latent attachment and simply involved a familiarity with the store and recall dimensions of pedantic knowledge transfer. Non-Likert derived statements accenting significance included, "I learned new knowledge related to my employment focus", and "the exercise validated to me that mathematics was difficult". This didactic application and validation measure was limited merely to passing the 57-question test. This 'meeting of the minimum standard', however, fails to address rich learning using multi-sphere evaluations.

As well, EFA yielded an important third axis labeled as 'Non-Conventional Lesson Delivery' (Factor 3). This factor presented high to moderate loadings incorporating the sub-variable themes: 1) situated PV as a new experience $\left\{0.68^{9}\right\}$, 2) educational development $\left\{0.62^{9}\right\}$, and 3) 'awareness' of the exercise $\left\{0.49^{9}\right\}$ (Table 2) ${ }^{9}$. Informant responses reflecting this third factor rank included, "it was a complete learning 'awareness" and "there was an increased attention - both voluntary and demanded by being there". Engaged knowledge construction appeared to enhance participant understanding documented by video and students who affirmed they were "examining the concept of a watershed differently as the exercise opened my eyes to humanity's cost and use of nature", and "I've lived in northern Manitoba all my life but have never crossed a flowing stream. I was terrified and in awe at the same time. I won 't forget it". This third axis, accounting for a less substantial but still meaningful $10 \%$ of the total variability, eventually would provide the naturalistic 'base' from which a proposed model framework would be considered.

Four overriding and signifying model levels were excavated from hundreds of vibrant theme cluster offerings (Table 3). These theme clusters, evocatively interwoven through digitally captured componential statements from both interviews and student-directed instream videos, included: 1) being situated and working collaboratively considered the 'catapult' for; 2) experiencing an improved 'awareness' and perhaps some potential for an elevated level of consciousness or internal self-inspection - leading to the procurement and securing of; 3) a complex 'postulate of adequacy' desire for competently demonstrating acquired knowledge, field-technique and understanding which sequentially was related to; 4) exhibiting activity-sensitive behaviors inclusive of concern, good will and ecological conscience. This very methodicity, producing these four rather pure but distinct theme clusters hinged on the powerful visualist epistemologies and language of the students themselves. 
Table 3. Hierarchically structured interview cluster codes (i.e., platforms) listing total number of participants ( $\mathrm{n}=97)$ responding to each attribute.

\begin{tabular}{|c|c|c|c|c|c|c|}
\hline \multirow{2}{*}{$\begin{array}{l}\text { Model Level } \\
\\
\text { Theme Cluster } \\
\text { Combinations }\end{array}$} & $\begin{array}{c}1 \\
\text { Experiential } \\
\text { Model base } \\
\text { (Sustenance, } \\
\text { embeddedness } \\
\text {-the } C_{\text {atapult) }}\end{array}$ & $\begin{array}{c}\mathbf{2} \\
\text { Long-term } \\
\text { Takeaway } \\
\text { (Conscious } \\
\text { internal self- } \\
\text { inspection) }\end{array}$ & \multicolumn{3}{|c|}{$\begin{array}{l}\text { 3 } \\
\text { Knowledge Learning and } \\
\text { Skill Acquisition }\end{array}$} & \multirow{2}{*}{ 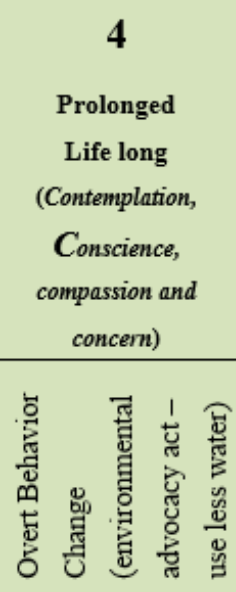 } \\
\hline & 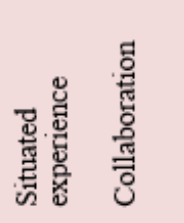 & 密 & 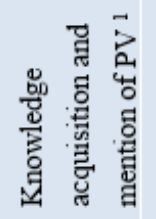 & 总 & 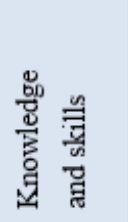 & \\
\hline $\begin{array}{l}\text { Number of mentions } \\
\text { during Interview ( } n \text { ) }\end{array}$ & $79^{3}$ & $65^{7}$ & $74^{8}$ & $58^{9}$ & 91 & $25^{10}$ \\
\hline $\begin{array}{r}\text { Place-based } \\
\text { Experience }\end{array}$ & $59^{4}$ & & & & & \\
\hline Positive Experience & $52^{4} \quad 38^{5}$ & & & & & \\
\hline $\begin{array}{r}\text { Positive Experience } \\
\text { plus Learning }\end{array}$ & $32^{4}$ & & & & & \\
\hline $\begin{array}{r}\text { Negative } \\
\text { Experience }\end{array}$ & $4^{5}$ & & & & & \\
\hline Exercise & 'awareness' & $33^{6}$ & & & & \\
\hline Environment & 'awareness' & $43^{6}$ & & & & \\
\hline One's self & 'awareness' & $62^{6}$ & & & & \\
\hline & Menti & ned (once) & 26 & 43 & & \\
\hline & Mentio & aed (twice) & 25 & 14 & & \\
\hline & Mentioned ( $t$ & iree times) & 14 & 1 & & \\
\hline & Mentioned ( & cour times) & 1 & & & \\
\hline & & & 'No chang & e' actual & $y$ stated & $18^{10}$ \\
\hline $\begin{array}{c}\text { No Mention } \\
\text { (during interview) }\end{array}$ & $18^{4}$ & $32^{7}$ & $23^{8}$ & $39^{9}$ & 6 & $54^{10}$ \\
\hline
\end{tabular}

$1=\mathrm{NFU}-$ necessary for understanding; ${ }^{2}=\mathrm{MFP}-$ mandatory for procedure skills.

Theoretical and methodological assumptions necessary to describe and design the logic for relating empirical test score data to mixed propositions were that, within any educational domain, a system of elicited behavioral categories may be uncovered and the features presented as a hierarchical taxonomy. In sequential context and by oriented definition then, the stream-discharge calculation exercise was 'foundationally' situated and collaborative, providing an experiential and catapulting base for three progressive and signifying clusters (or platforms) remaining in this proposed learning model's framework.

In due course, from surveying hundreds of PV and interview responses, a resulting four-level hierarchical model conceptualization evolved to express local student learning. Importantly, classically unrecognized and unevaluated behavioral dimensions were, made 'visually' available in this ethnos-scientific analysis of literal statements transformed into codified digital clusters (Table 3). When presented in diagrammatic form, the relational properties of this terminological system are available at a glance, showing a theorized cognitive pyramid and prospective model for consideration (Figure 4). 


\section{Overt Behavior Change (n=25)}

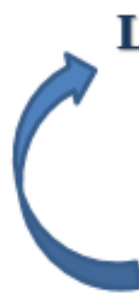

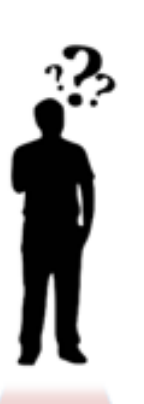

Environmental Advocacy

The Phenomenon of Interest Sustaining Latent Concern Life-long 'Long-term' Takeaway Compassion and Conscience Attitude - Belief - Intention

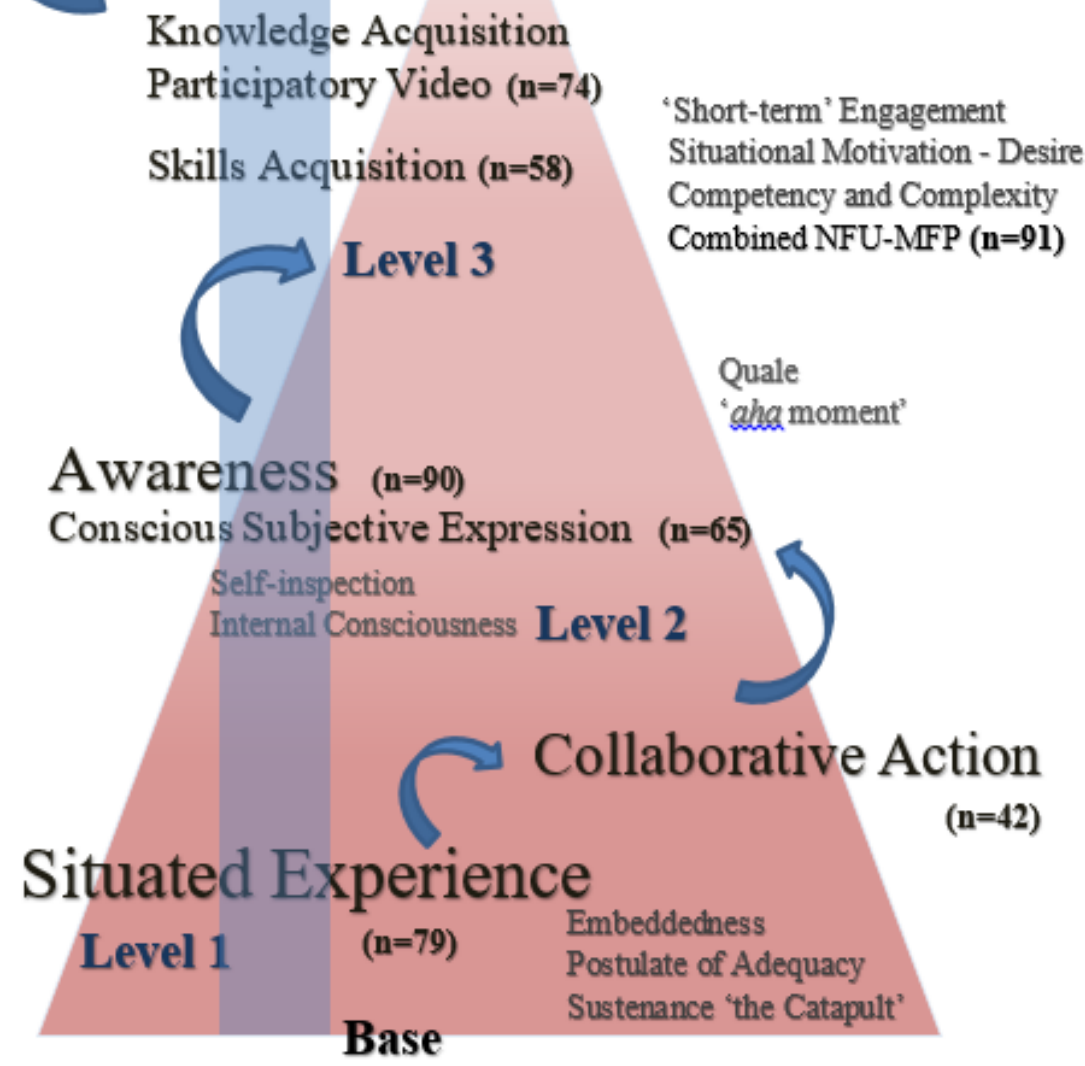

Figure 4. Posited model of hierarchical platform development and associated participant response numbers from a total of ( $n=97)$ participants (i.e., 79 of 97$)$.

In sequential description, in-situ sustenance provided by being situated and embedded (Base-Level 1) and using a mediating technology, acted to catapult participants towards a new 'awareness' and some potential for elevated levels of consciousness (Level 2). In turn, stream-level interaction was expected to trigger self-examination, 'scholastically-marginalized' in conventional rote lesson assessment. Progressively, students were posited to be elevated from this new situated consciousness towards an improved level of awareness and co-motivated desire to acquire the necessary complex knowledge and technical skill required for competent stream discharge calculation (Level 3). These three preceding levels would subsequently provide an hypothesized opportunity for each participant to then contemplate a 'self-sustaining' intention (Level 4), kindling a measure of self-actualization or overt transformational 'take-away' and lasting impression into new behavioral domains.

As behavioral 'competence' (Level 4) was the evaluative emphasis, the presumption was that in order to communicate and be assessed 'successfully', participants must express 'normative' and codified tenets, or themed statements as adult learners (Table 3). Measured in the semantic system of an environmental discipline, it was assumed eco-friendly behavioral 'fitness' could be approached indirectly through the PV medium and the ordinary usage of vernacular terms (or signifiers) chosen by the students. Spoon (2014) explains colloquial speech within such ethnosemantic frameworks cradles the philosophical concept of 'intentionality' laying the foundations for 
moral compassion, concern and benevolence. In accordance with Geertz (1973), this series of ethnosemantic examinations would be the social and investigable organization of student perceptions evident in the expression of their beliefs during this experience.

Definition of each readily discernible model platform and speculative explanation formalizing each of the four serial stages for an ordered and hierarchical positioning follows.

\subsection{Model Level 1 - A Naturalistic and Experiential Base - the Catapult}

Unsolicited interview results indicated 79 and 42 of 97 participants mentioned some aspect of the in-stream activity as being foundationally situated ${ }^{3}$ and/or collaborative ${ }^{3}$, respectively (Table 3$)^{3}$. In cognitive science, the term situated refers to an agent (i.e., student) embedded in an environment. This initiating place-responsive perspective was hypothesized to emphasize a 'base' proclivity or potentiality for informed overt behavior (i.e., a personal sense of environmental advocacy) derived from lesson delivery, the environment, and a student's focused interaction with each. Recall the theoretical proposition here was that a match in knowledge, skill and perhaps overt behavior would be refined and focused via PV development and situated facilitation (Plate 4). Both Lave and Wenger (1991) and Wilson (2008) support this theoretical and regional underpinning.

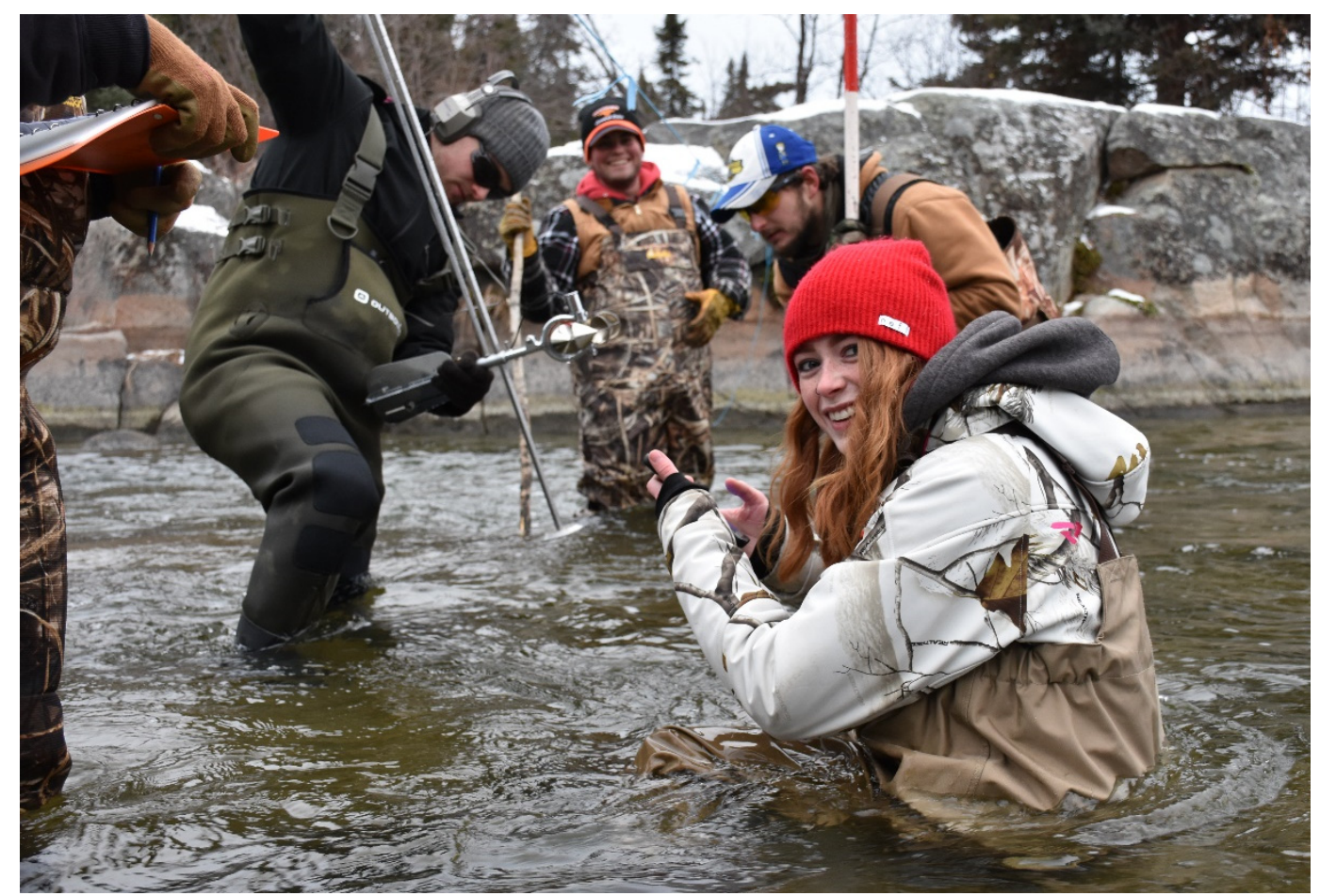

Plate 4. Opportunity encouraging behavior believed 'healthy' for place-sensitive 'awareness' and ecological sustainability.

By definition, non-Likert participant response sub-codes for being situated included: 1) a foundational place-based experience $\left.\{\mathrm{n}=59\}^{4} ; 2\right)$ a positive environmental experience 'without' mention of related learning $\left.\{\mathrm{n}=52\}^{4} ; 3\right)$ a positive environmental experience 'with' mention of learning $\left.\{n=32\}^{4} ; 4\right)$ a negative outdoor experience $\{n=2\}^{4}$; and 5) no mention of the experience during the interview $\{\mathrm{n}=18\}^{4}$ (Table 3$)^{4}$. Delineating procedural and analytical significance in theme coding, students referring to the positive nature of a place-based experience 'with' and 'without' mention of learning stated, "participating was a complete learning 'awareness"' and "being in the cold and snow was peaceful - it was a less strict environment".

Addressing situated context four decades ago, Garfinkel et al. (1981) similarly advocated an activity must be 'tied' to some experiential emphasis. Hence, facilitating details of an activity 'in context' provides for it being 'seen' as a respondent's instinctive reply to a challenge. Making sense of any associated social knowledge while exhibiting place-sensitive behavior is therefore something that must be accomplished in-situ. According to Rasheed et al. (2020), this related place-based emotional development does not happen haphazardly, but rather through engagement in methodologically situated practices of making sense. Consequently, 'where' and 'how' knowledge 
is delivered, and sequentially acquired, is plainly of relevance to helping learners reach a moral destination with social connection (Plate 5).

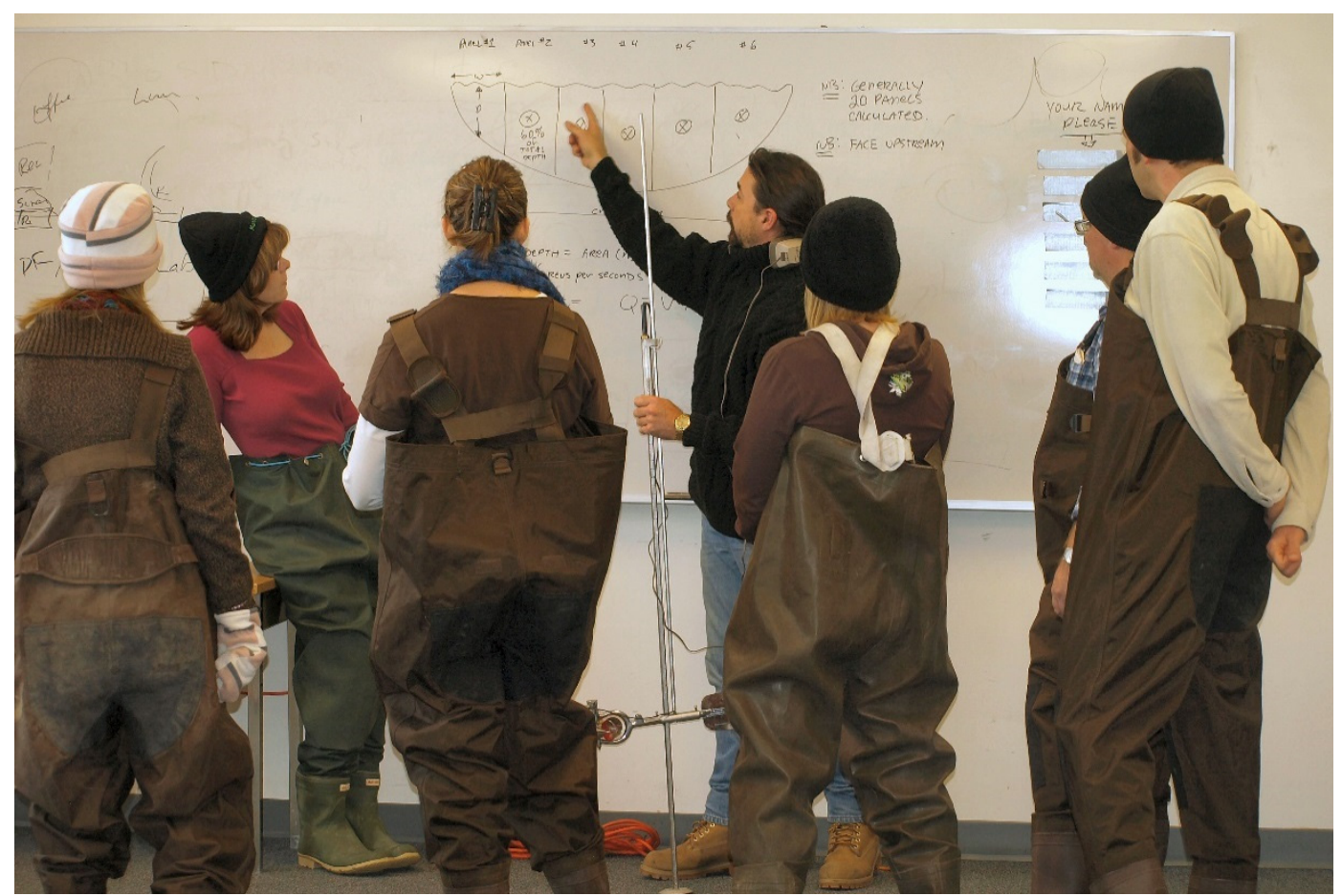

Plate 5. Business administration students engaged in didactic learning.

Foundationally, the stream exercise simultaneously incorporated an element of collaboration, defined as working together to achieve success by sharing knowledge to build group consensus. Unsolicited responses coded as being 'collaborative' included: 1) a positive collaborative interaction $\left.\{\mathrm{n}=38\}^{5} ; 2\right)$ a negative collaborative interaction $\{\mathrm{n}=4\}^{5}$; and 3) no mention of collaborative interaction during the interview $\{\mathrm{n}=55\}^{5}$ (Table 3$)^{5}$. Most references to collaboration were positive in nature. For instance "as a group there was completion most likely not possible by myself" and "I'll be more confident doing jobs and school assignments when we are in groups and working together and stuff - I know now that I am better working with people". In contrast, negative references cited "there was a struggle for leadership" and "I felt I was not part of the group".

Although most collaboration requires leadership, group form was assumed decentralized and egalitarian for this short-term task. Teams that worked co-operatively were inferred to obtain higher scores; a method specifically aimed to encourage introspection, increase traversal skills and academic success (Plate 6). Simply, collaboration was perceived a recursive process, but in some instances ... much more was acquired. For instance, "I certainly will take risks. I've always been a team player but I certainly think that - I usually pick my team - if we're in a big group or something like that. There are certain people that gravitate towards me or that I gravitate towards - now I think that I just might be more inclined to try somebody different for a change - I think it is a learning experience". 




Plate 6. Mutual stability in turbulent currents.

Being situated and working collaboratively, in this logic, provided opportunity where colloquial speech was 'culture defined' and where subsequent evaluation included cognitive reference to knowledge and belief held about specifiable spheres of life, intention and accepted reciprocal conduct. Defined by Goodenough (1957, p. 167), " $a$ society's culture consists of whatever it is one has to know or believe in order to operate in a manner acceptable to its members". Similarly, to Lave and Wenger (1991), the task of ethnographic description is specification of the knowledge and belief necessary for an individual to operate acceptably in a group. Pared to its scientific essence, 'culture' defined here comprises nothing more than behavior patterns shared by members of a group that rely on socially transmitted information necessary to complete the activity (Plate 7). In this sense, PV unbiasedly advocated a close investigation of environmental and ethical reasoning, rather than re-representing the typical portrayal of northern culture and ill-assessed grade point labelling impacting an individual's academic trajectory. 


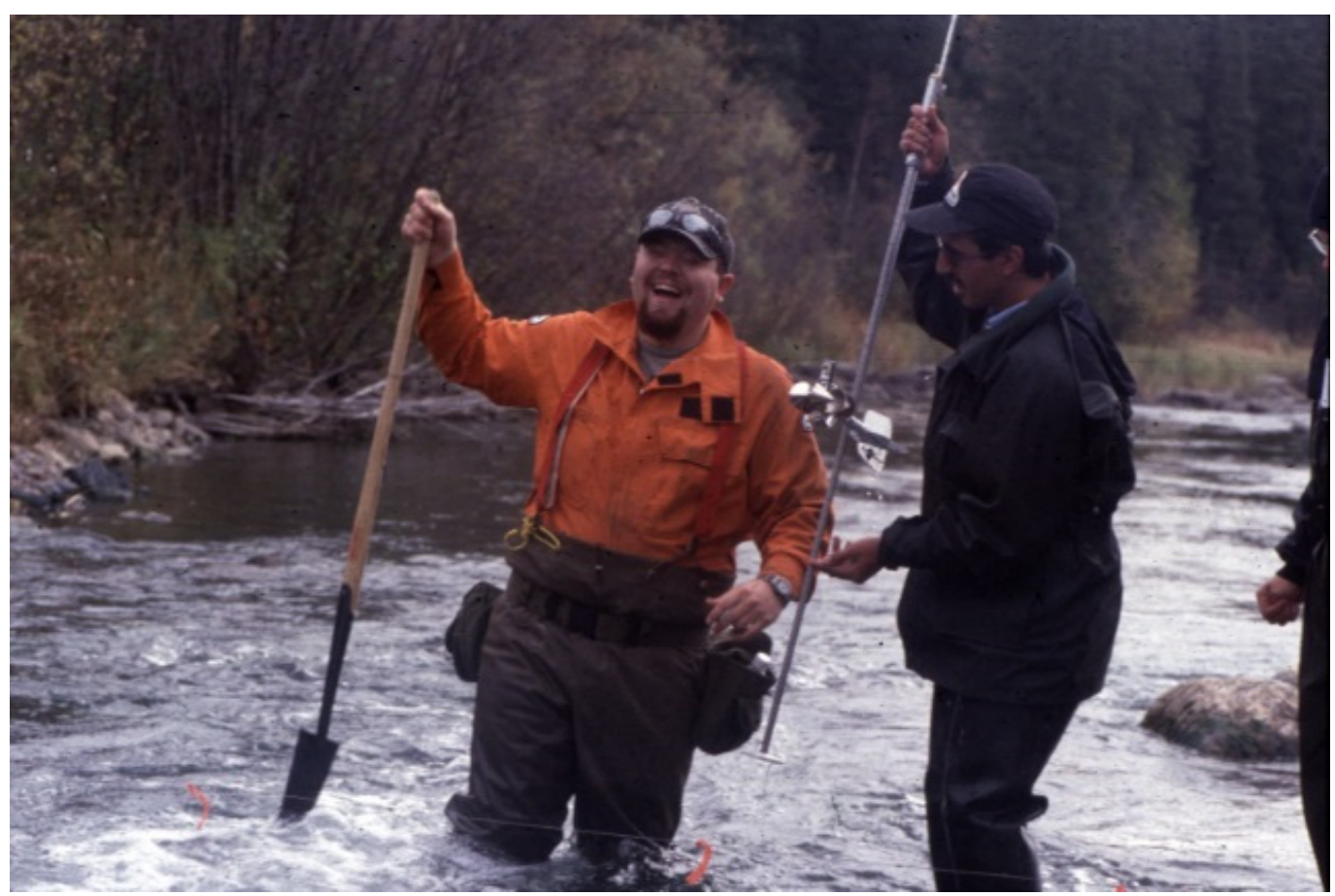

Plate 7. A shift of consciousness that permanently alters our way of being in the world.

\subsection{Model Level 2 - 'Awareness' and Quale - Conscious Self-Inspection}

Following the in-stream opportunity for learning being situated and collaborative (Base Level 1), active participation provided not only an increased 'awareness' but presumably a potential for capturing some 'elevated' level of consciousness. This 'awareness' and perhaps subjective 'aha moment', represents a successive and second level of scaffolding in model conceptualization (Figure 4). Emerging unsolicited responses coded as simple 'awareness' included: 1) 'awareness' of exercise $\{\mathrm{n}=33\}^{6} ; 2$ ) 'awareness' of environment $\left.\{\mathrm{n}=43\}^{6} ; 3\right)$ 'awareness' of one's self $\{n=62\}^{6}$; and 4) no mention of being aware $\{n=7\}^{6}$ (Table 3$)^{6}$.

In total, 90 of 97 candidates referenced some type of amplified 'awareness' while 41 mentioned more than one aspect of being aware. These new understandings reflected the local significance of northern place-sensitive freshwater conservation and perhaps a shift from homocentric understandings with respect to the sustainability of freshwater in remote communities. For instance, one informant noted "shock in government non-regulation and the lack of [resource-related] education in high-schools". Another referred to added dimensions of flexibility and tolerance stating, "it was difficult to step back - I am more accepting of others 'perspectives now". Inarguably, it is unlikely students would be provided opportunity or be prepared to engage in these biocentric and personal contemplations, still less, be expected to practice them, unless appropriate opportunities for local experiential learning and expression via PV were provided (Plate 8). 


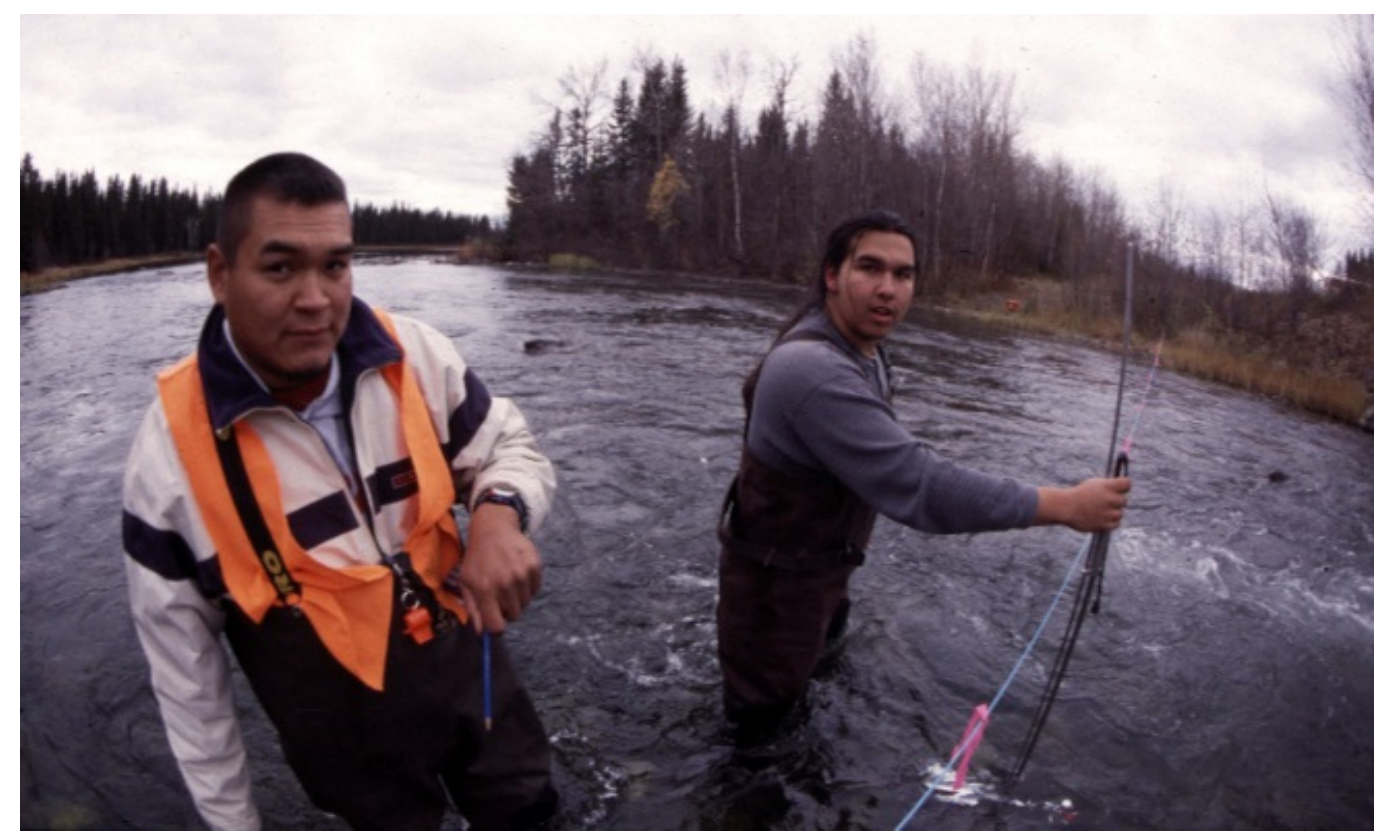

Plate 8. Stream monitoring provides increased 'awareness' and potential for elevated consciousness and postulate of adequacy relatability.

By definition, 'awareness' is considered the ability to perceive or be conscious of events or patterns culminating in established 'mindfulness'. Essentially, a participant may be subconsciously aware or acutely aware of an event. Broadly, it is the state of being cognizant of 'something' (Wyart \& Tallon-Baudry, 2009). In biological psychology, 'awareness' forms the basic concept of the theory and practice of Gestalt therapy; but in general, 'awareness' is described as a relative concept referring to public, common or lay understanding of a specific social, environmental or scientific issue (Brownell, 2010). Principally, this was a descriptive task to clarify and analyze statements related to watershed 'awareness' while measuring the concerns and values underlying each.

According to Husserl (2012), experience as it occurs visually, always encompasses 'something more' including abstract phenomena like emotions, intentions and memories. As such, Sorenson (1975) suggested we would be wise to visually document ephemeral varieties of patterned behavior to provide humanistic insight and a more controlled formulation of educational understanding. For this reason, my interest in this learning experience, encompassed what was 'felt' by the students and how it could be recognized, digitally and empirically. In short, my concern was analytically treating how these respondents became aware as part of their experience while standing waist deep in a flowing boreal stream. Interestingly, because this video process was richer in phenomenological expression, any viewer can more readily relate the insights and information being presented in this model to their own sense of reality.

Catalyzed by 'reality' and defined as a 'disorienting dilemma' (Mezirow, 2000), 'good learning' (Newman, 2010) or 'soul work' (Jung in Kovan \& Dirkx, 2003, p. 102) - 'awareness' may also be focused on an 'internal state' (a visceral feeling) from participating in such an exercise. Newman (2010) and Mezirow (2009, p. 28) acknowledge many experiences occur outside 'awareness' where sensation may substitute for critical self-reflection providing the raw material or 'quale' from which participants may develop constructs of transformative considerations. Probabilistically, within each participant then, there could be an elevated potentiality for "certain features of the bodily sensations especially, but also of certain perceptual experiences, which no amount of purely physical information includes" (Jackson, 1982, p. 127). The term quale refers to this 'raw feeling'. Personal examples are my Mom's plight to inexpressibly describe symptoms for her restless legs, or in memory, the tasting of my Dad's November Deer Stew. Perhaps for some of these students, the experience of participating in the calculation of this river's discharge and wearing a pair of rubber pants provides something more?

Subsequently, unsolicited references to this internal state or 'something more' during the interviews were binomially categorized as either: 1) statements of a conscious subjective and transformative experience $\{\mathrm{n}=65\}^{7}$; or 2) no mention of such an experience $\{\mathrm{n}=32\}^{7}$ (Table 3$)^{7}$. As such, students were often 'concerned' about their wellbeing and/or the local state of freshwater. Signifying statements included, "I felt less hope and less in control 
knowing this information", "I have an awakening regarding my attention, caring, and concern for the environment. I have been thinking about the world more, not simply myself and this town - we must smarten up as I sadly found garbage and keys in this beautiful stream segment we researched - in the middle of nowhere!"

Hence, in this boreal stream, each 'embedded' student had the opportunity to experience some level of 'awareness', subjective quale, or expressions of eureka while collaboratively being exposed to a new learning environment. Either way, with video camera in-hand, it was posited that in some instances, students would be circumstantially motivated to advance from a situated-driven 'awareness' or consciousness to a new desire for increasing 'their' pragmatic and technical skills with respect to their surrounding 'community of practice'. Palmer (1997) suggested this motivation is a 'prescriptive element' in peer and ethical thinking where participants offer each other guidance or rules about what might constitute ethically correct behavior toward the environment and what kinds of actions are 'right or wrong'.

\subsection{Model Level 3 - Motivation for Knowledge (PV) and Skill Acquisition}

In platform succession, ninety-one of 97 students referred to some new aspect of combined knowledge and skill acquisition. References specific to knowledge acquisition (inclusive of PV learning) as one possibility for advance were coded as: 1) mentioning knowledge gain once or multiple times - where responses were ordered $\{\mathrm{n}=74\}^{8}$; or 2) making no mention of knowledge gain $\{\mathrm{n}=23\}^{8}$ (Table 3$)^{8}$. Many students indicated knowledge acquisition related directly to non-conventional lesson transfer. For instance, "I've never experienced anything like this - others were really excited when I told them what I was doing", and in some cases specifically to the use of $\mathrm{PV}(\mathrm{n}=12)$, "using the camera helped me to realize it more" (Plate 9).

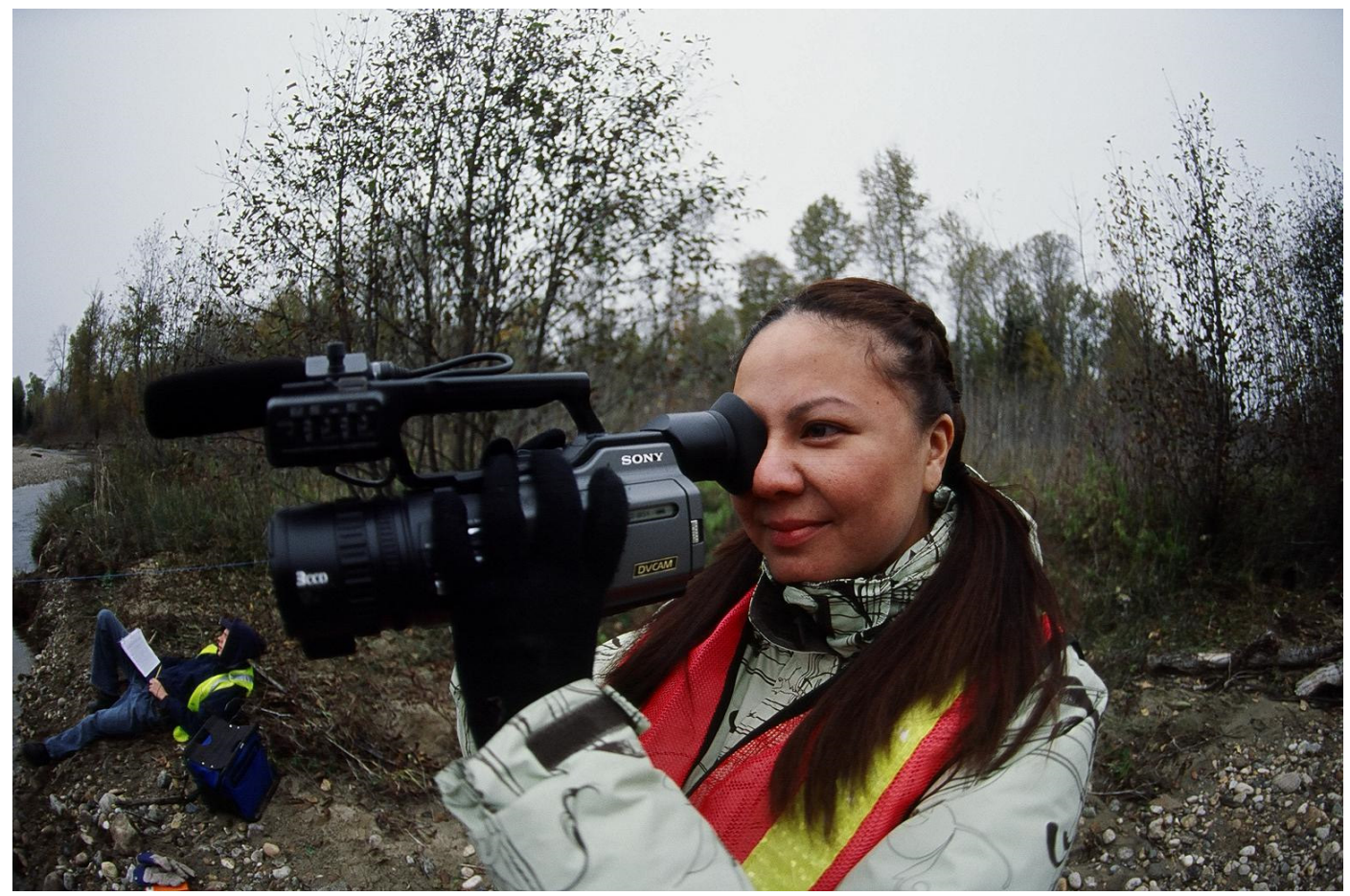

Plate 9. Participant using PV technology with "the push of a button".

These dozen or so unsolicited statements relating to video provide evidence for how visual technology may be used to extend the range of lesson delivery to learners with visually oriented avocations. Photographic imagery, like language, contains subtleties difficult to express via conventional linguistic approaches (Sorenson, 1975). Hence, it was particularly rewarding to examine current environmental challenges by means of visual documentation and assessment considerations. Responses were more accurate, less inhibiting and less 'rigged' than replies to conventional questionnaires. Participatory video provided an exceptionally rich source of information in assessing these new evaluative dimensions.

Preliminary and unrefined knowledge acquisition sub-codes included: 1) new experience and PV; 2) knowledge sharing; 3) educational development; 4) social responsibility; and 5) environmental knowledge (Table 1). 
Regarding 'educational development', participants revealed "others made me realize I need to ask more questions and a greater variety of questions while participating in class" and "I will make provisional increases in opportunity for environmental curriculum when I am a teacher". Likewise, 'improved learning strategies' were frequently mentioned: "I realized a strategy - that is from situation to lecture setting rather than the reverse, so I will now try to do more in clinical setting as this was an easier way to learn" and "I thought of myself as an indoor learner but outside was fun".

Alternatively, and as a conjoined route for Level 3, unsolicited references to skills acquisition were coded as either: 1) skill acquisition $\{\mathrm{n}=58\}^{9}$; or 2) students making no mention of skill acquisition during the interview $\{\mathrm{n}=39\}^{9}$ (Table 3) ${ }^{9}$. Unrefined sub-codes included: 1) skill development; 2) personal development; and 3) improved learning strategy (Table 1). Students recognized skills were inextricably linked to future opportunity stating, "these skills will certainly improve my chances for career development" and "I realized my leadership capability of taking charge of a group of people".

Employability skills are defined here as transferable skills needed in the job market, along with pre-requisite technical understanding, self-awareness, flexibility and concepts of numerical interpretation (Mace \& Bacon, 2019). Essentially, a group of abilities that involve the development of a knowledge and skill base, technical expertise and mindset that are increasingly necessary in the modern 'workspace'. These skills are essential for even seasonal positions in northern Manitoba (i.e., Initial Attack) and hence are necessary for regional success. Extrapolating with respect to model positioning, it was assumed 'awareness' and quale (Model Level 2) were not only 'pre-requisite' to Model Level 3 (e.g., the desire or need for complex knowledge and skills acquisition) but for private learning and behavioral transformation as well.

\subsection{Model Level 4 - Overt Behavior Change}

Procedurally, personal overt transformative behavior was the definitive outcome in this conceptualized hierarchy of factored themes (Figure 4). That is, following the discharge activity being situated and collaborative (Base Level 1), the idea that place-sensitive participation provided for an elevated level of 'awareness' (Model Level 2) and a desire to accrue 'new' knowledge and skill (Model Level 3), there was a private potentiality for each student to have ignited an 'overt and self-sustaining' expression of environmental decency (Model Level 4). Analytically, however, the latter would have to be recognized as some normative visible and measurable overt act; a personal insight that students 'take with them' relating to something 'beyond' and life-long (Mezirow, 2000).

For instance, one student referenced insights regarding interaction stating, "the activity made me realize my perceptions about those two people prior to the exercise were biased - were not accurate - that their behavior during the exercise challenged the perceptions I had and I found that affirming for them as group members but also reminding me that I shouldn't assume my perceptions are fully accurate. I've actually went to one of the two group members and I thanked them for taking that active role and that I appreciated that it was helpful for me and I think that it will make me more open to doing similar things in the future".

This and similar unsolicited references coded as transformative behavior change during the interviews were subcoded as: 1 ) an overt positive act $\left.\{\mathrm{n}=25\}^{10} ; 2\right)$ a stated 'no change' in behavior $\{\mathrm{n}=18\}^{10}$; and 3 ) no mention during the interview $\{\mathrm{n}=54\}^{10}$ (Table 3$)^{10}$. Behavioral intentions related to these UCN student experiences and non-Likert response codes were reflected in unsolicited video statements as "the way I've viewed water as a resource - just from a general person's perspective - I've lived in plenty of beautiful places where - you know - perfect little pristine streams like that flow just about everywhere - however, standing in there and actually metering the river itself and figuring out the discharge of the river - kind of makes it touch home a little bit more than just kind of watching - and it just makes me think you know we've really got to try to save these precious resources" (Plate $10)$. 


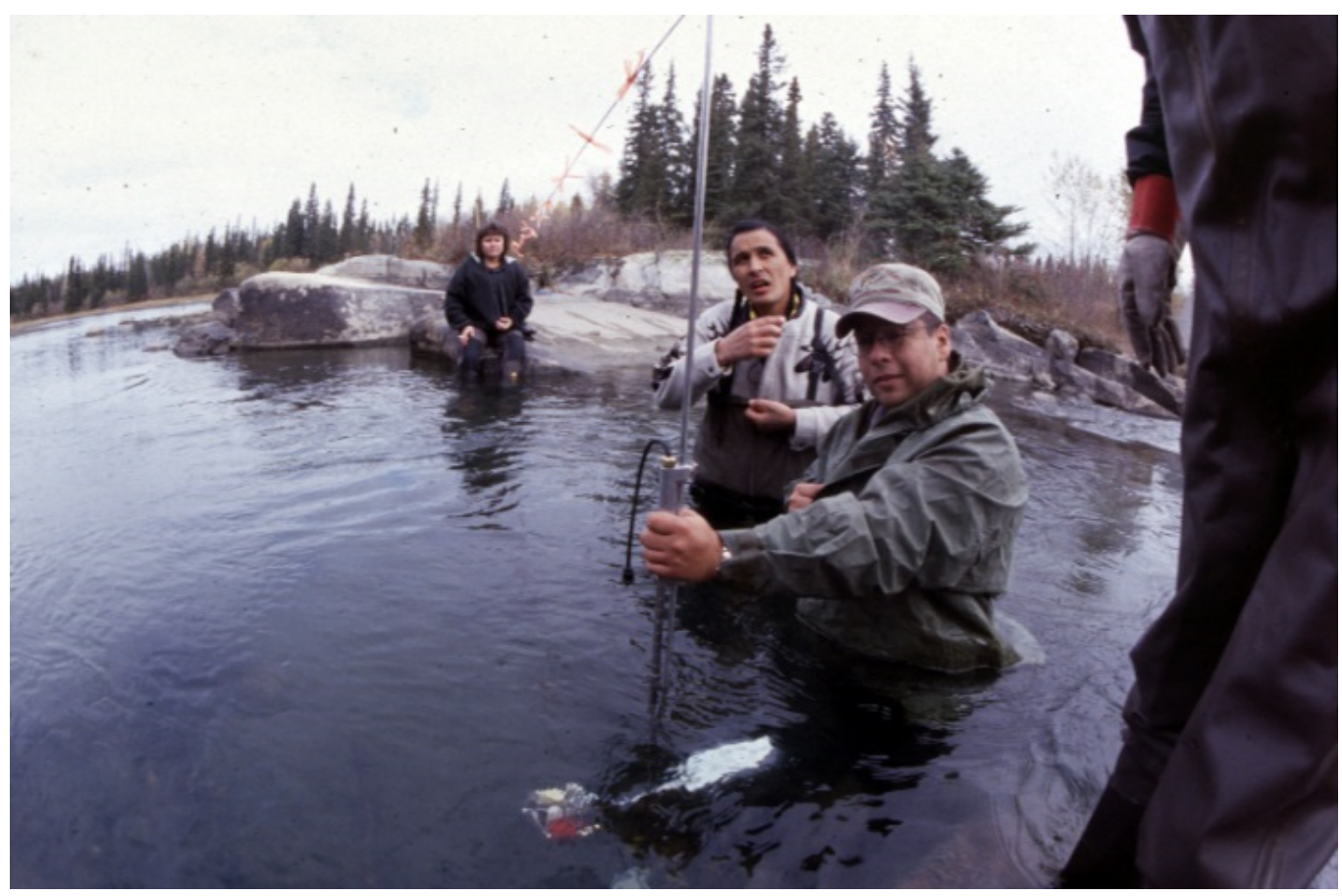

Plate 10. Students incorporating deep experiential reserves of knowledge opening a realm of competency possibly eluding literates.

Operationally, an 'overt' behavior change (Model Level 4) refers only to 'normative' manifest actions of the students in relation to lesson delivery, the surrounding environment and acquired knowledge. That eco-morality is influenced substantially by situation, context, and lesson delivery, there is no doubt. Subsequently, it is important to note student observations implied knowledge and skill acquisition had associated cultural, place-sensitive and affective components. Although some dexterity with narratives was evident on the part of these reality definers, I suggest identification and examination of behavioral change is probably the most significant finding in this study and in many respects, its main contribution.

From the point of view of developing a 'more' integrated theoretical insight into student assessment, it is important then to grasp these dynamic understandings of constructs and place them in a coherent set of supra-ordinate categories. Perceptibly, these UCN student findings provide evidence of a facilitative and evaluative gap when assessing remote based student performance as each Indigenous participant's behavior was inextricably linked to their pre-tertiary experiences, agentic values and 'regionally infused' paradigms.

Unfortunately, there has been rather limited attention focused on establishing how facilitating student transformation might take place. The intention certainly is not to suggest morality is completely denied in the classroom, but rather that it is marginalized in didactic environments. I can relate this lesson amoralization to Bauman and Bauman's (1993, p. 30) notion of adiaphorization where authorities do not feel it necessary to make a stand. Sadly, this attendant denial of responsibility for the surrounding environment is effectively shaped by the context in which it is 'packaged', even here in northern Manitoba.

With this evidence-based paradigm in mind, the following section will discuss these findings, theorize about them and draw out implications and conclusions, because as illustrated, becoming aware and acquiring new knowledge, skill and morality are in many important respects, inextricably entwined. Pivoting to identify non-conventional dimensions of learning that students care about and better assessing related constructs will provide a much richer opportunity for regional education and its affirmation. Hence, it is apparent from this investigation into unsolicited insights that UCN students from the most remote northern communities have an ample store of meta-ethical insight to be valued scholastically - each northern participating soul helping to transform educational assessment in affirming ways.

\section{Discussion}

Contextualized by situated accomplishment and chronicled using participatory video (PV) as a mediating ethnosscience, discussion of these integrated findings reveal exciting learning trends based on empirical test scores and 
allied quantified affective insights arising from unsolicited UCN student response to four comparative and tested lesson deliveries. Missing from previous scholastic charge (Stepaniuk, 2019) was a meaningful measure to gauge these same students using something 'extra'. As isolated adult enrollees are multidimensional, and scholastic 'empirical-ization' does not occur in straightforward ways (Ellsworth, 2005), appropriate interest in curricula considerations that change the student are critical as it is in these remote communities that global to local freshwater ignorance is felt most directly and where non-traditional edifying initiatives will accomplish the most.

Although some educators regard this sense of 'emergence' as having only a pseudo-scientific status (Emmeche, 1997), new teachings at cross-disciplinary institutes focus strongly on high-level 'collective behaviors' in complex systems augmenting, evaluating and making sense of lesson deliverables (e.g., the Natural Resources Institute at the University of Manitoba). For UCN, attention is similarly on coalescing affective hermeneutic understandings in educational features ranging from enrollee ambitions to credit transfer, fore fronting decision-making profiles of Indigenous adult learners and 'their' academic aspirations. Based on mature learner need to connect with credentialed grade point averages (GPA), these UCN mixed in situ findings make the case contextual 'emphasis' is necessary in prescribed andragogical training and assessment.

By design, exploratory factor display of such eco-sensitive conduct expressing itself as a latent variable, captured some local universe of the Indigenous behavioral construct targeted. In the following paragraphs, I discuss assessment of these attitudinal 'extras' with respect to: 1) exploratory factor 'ordering' specific to UCN; 2) metaethical processing and the use of PV; and 3) how normalized psychometric declarations of students are defined in four conceptualized hierarchical platforms helping to signify a north-sensitive theory. In sum, diverse and clustered statements correspondent with improved environmental 'awareness' support originally forwarded hypotheses that: a) different lesson deliveries connect theory to scholastic ability while PV helps to parameterize mixed findings; and b) situate opportunities stimulate latent ecologically intelligent literacies, attitudes of advocacy and behaviors typically denied scholastic meaning in postsecondary environs. Given declines in government support, implementation of 'alternative' academic designs in environmental education present a viable strategy in the North.

\subsection{Factor Ordering}

Although grade point average (GPA) brands student 'ability' provincially, a latent sense of private advocacy via streamside engagement (Factor 1) rated highest in UCN student 'factor' importance. In essence, as these 97 northern participants offered their existing philosophies, scholastic success was dominated 'not' by a specific quantitative attribute nor empirical test score (Factor 2), but something mixed and normative, reflecting placesensitive environmental 'awareness and attitude' as an academic outcome of lesson transfer. These same 'empiricalized' affective omissions from current learnedness and GPA have been realized salient for some time (Dewey, 1938; Manning \& Harrison, 2018). Those concerned advocate applied practices are the undergirding of sincere erudition and that socio-environmental approaches to learning must be of the right context to evoke passion and emotion (Rey \& Harrison, 2018). Regrettably, retaining specific privilege in academic labeling of northern Manitoba Indigenous students are disembodied curricula and unresponsive grading schemes, restraining evaluative scope, moral image and credit transfer (Mercredi, 2009; Martin, 2014).

In similar contrast to conventional criterions, aspects of UCN's non-conventional lesson delivery (Factor 3), as well, provided diverse elements of quantified emancipatory 'givings', accounting for significant improvement in academic success. With related insight into liberal learning from an institutional perspective, Wright and Sandlin (2009) reflected on these same needs to provide something equitable and high quality that includes participating in situate vicinities preparing graduates for an acute analytic citizenry. According to Richardson (1994), allowing opportunities for personal expressions leads to principled habit-forming wisdom in self-elected domains. Hence, until students experience the concept of verisimilitude, there can be no agreed upon lesson methodology for a moral 'postulate of adequacy' acquisition.

Lave and Wenger (1991) likewise propose entry-level participation in a culture of rehearsal entail observation and learning from 'boundary' positions. In UCN-specific factor sequence, as riverine engagement increased, candidate enrollees advanced from the role of situated observer to functioning agent (i.e., legitimate peripheral participation), progressively integrating into streamside culture to determine what was required for group membership. Lave and Wenger established early that a critical aspect of applied lesson theory, is to participate in a legitimately peripheral way, such that entailing "newcomers have broad access to arenas of mature practice" (p. 110).

Awkwardly, scholastic ability (Factor 2) reflecting an institutional familiarity limited to 'making the grade' presented as less important empirically. Although Andrich and Styles (1994) suggested pedantic development is analogous to methodical 'salmon leaps' in reasoning, they found no cognitive synergy when didactic methods used to 'pass the test' were exclusive. Rather than enabling students to 'leap' analytically, rote lecturing reduced re-test 
errors making genuine student progress difficult to assess. As early as 1972, Bligh noted that rote designs and associative multiple-choice questioning did not allow for notions of unanticipated learning. Likewise, this UCN 'factor-order' casts doubt on several established assumptions regarding northern Manitoba erudition, shifting new lesson inquiry towards consideration of blended designs, the purpose of question structure and the gathering of wider information on the meaning-making abilities of isolated adult learners.

Animatedly, these UCN factor order findings may be considered in terms of a mental reference to threedimensional lesson navigation in a boreal streamside learning 'galaxy', as opposed to being confined in didactic transfer as two-dimensional discharge calculation notations passively radiate from whiteboard to recipient. What these results offer is in some way similar to Gibson's (1966) concept of 'affordance', or what UCN chooses to present to its enrollees as transactional and transformational forums. If, for example, the metaphorical Necker cube (representing lesson type) were oriented so its 'edges' coincide, lecture dissemination would likely be perceived as experientially 'flat' (i.e., square). Instead, as lesson (or Necker cube vertices) move from one to another in the situated commotion of a located 'space', immense configurations of place-responsive knowledge, skill and emerging attitude are permitted to collectively circumvent perceived barriers via relational learning through 'other lenses' (Ellsworth, 2005; Palmer, 2003). Vicinity rehearsal, positioned perceptions and lively engagement inviting UCN students to connect with others in a fluvial discourse, enjoying the aesthetics of the ecosystem and thinking about their place within the watershed.

Nothing in an inactive didactic lecture can supply such bewilderment and since it is problematic to generate vast indispensable behaviors from in-class instructive transfer alone, a principal task of sustainable development curricular design is to 'use' what is available. That is, augmentation of scholastic advance being set in motion by the embodiment of a philosophy, rather than a subject of study (Fraser, 2015). This rather animated reasoning for UCN factor order suggests imported metropolitan- 'ized' lesson transmission be supplemented by local task and regional metonym if the intent is to gain deeper insight into Indigenous knowledge acquisition. Operationally, Gough (2005) provided comparable insight concerning barriers to students withdrawing and persisting in tertiarylevel environmental science programs more than a decade ago.

Helpfully, these mixed UCN results reveal a 'measurable' congruence between cognitive and affective student perceptions while academically documenting a variance in the nature to problematize using something extra. Indeed, the majority of this seven-program cohort was able to transition from empirical content to personal and participatory abstractions, indicating situated experience and associated in-situ paradigmatic shifts increase levels of private integration, inference and academic success. Grounded in Williams' (1967) notion that all culture is educative and Jarvis's (1992) idea that it is naïve to assume significant transactional learning is restricted to the classroom, these northern findings submit blended lesson designs are integral to perspective dissension as an imported didactic approach inevitably excludes some percentage of learners in this setting.

Recognizing the utility of these notions and that northern learners engaged in demand-driven activities displayed an overt need to express their emergent meta-cognitive behaviors while participating 'in streamside' and after the fact interviews, I too speculate UCN students experienced something more while confronting, analyzing and solving earthly important challenges. In fact, by partaking in non-traditional situate lessons, UCN participants exhibited significantly higher 'composite' test scores.

Grounded in more than two decades of facilitating Natural Resources Management Technology in Manitoba's north, I have witnessed that difficult-to-understand constructs $d o$ evolve in students erupting into seemingly disordered overt acts ignored by provincially regimented performance measures. As one meaningful response to the confluence of poor secondary education and the increasing numbers of migrant enrollees, unfortunate Indigenous scholastic consequences and ill-conceptions regarding environmental sustainability are incomprehensive at an institute geo-positioned as UCN.

\subsection{Participatory Video as an Ethnos-science}

As advances in technology enhance convenience, few educators are experimenting with digital video as a tool for assisting classroom learning (Rooney, 2007). On theoretical frameworks relating specifically to technologyassisted facilitation, Cottrell (2010) indicates participatory video (PV) projects tap into many aspects of scholarship, increasing cultural appreciation while enriching unexplored life perspectives that provide for transformational processing. Similarly, by recognizing digital technology as legitimate for more than just passively viewing in-class documentaries, I used PV as an ethnosemantic process to invite and chronicle UCN student interrogation of lesson delivery. In this northern setting, student-directed PV revealed trends and confirmed hypotheses in hermeneutic understanding, buttressed by allied and previously attained empiricalized evidence (Stepaniuk, 2019).

Centering on the analysis of a rich visual imagery for expressing in-and-post-field interview dimensions considered 
empirically intangible, quantified respondent 'signifiers' in captured video presented as academically persuasive. Student comments indicated a 'depth of decision' in response to lesson delivery, academic advance and regional freshwater use now fashioned by a local method for assessing context-specific competency in quantified loticintegrity. Shaw, Brown and Bromiley (1998) contend such 'stories' and activities are central to the categorization of situated understandings giving these UCN students the opportunity to express their 'awareness' (90/97), academic prowess (91/97), extra-rational experience (65/97) and notions for their transformational development $(25 / 97)$.

Operationally, and although Roulston and Lewis (2003) caution interview assessed dynamics are classically ruled by examiners, unsolicited responses bracketed UCN participant meaning while exploratory factor analysis (EFA) reduced 'normative' perceptions to a three-factor phenomenological description of local essence: a merged description so I as an assessor could grasp the "nature of the thing" (Van Manen, 1990, p. 177). Regardless of reader-perceived subjectiveness regarding this proposed model, digitally revisited and quantified responses were rich and empirically informative as binomial results based on participant experience were perceived free from researcher bias. If accepted, these UCN findings are transparent, coherent and communicable. Stated by Zinsser (2006), the participant's words "will always be better ... they carry the inflection of a speaking voice and the idiosyncrasies of how a participant puts a sentence together. They contain the regionalisms of a conversation and the lingo of a trade; they convey enthusiasms. This is a person talking to the reader directly, not through the filter of a writer" (p. 81). Hence, with a great deal to offer, PV permitted digital capture and review of regionally unique perspectives in streamside 'ceremony', creating a basis for entering into each student's private dialogue serving to forward and saturate a northern learning theory (Wilson, 2008).

With respect to coding, the digital repository of student comments had a powerful sway on how scholastic grades were expressed (i.e., Factor 1) and how method, data and theory would be represented. Interestingly, putting video technology into the hands of these students procedurally enhanced their focus when combined with either didactic (DPV) or situated (SPV) lesson transfer, but most evaluatively so with the latter. Kallis et al. (2006) affirm such processes play a central role in the description of indicators originating from awkward results, overlapping participant attributes and latent behavioral constructs. Overall, a strong video theme in these 97 student accounts relates directly to principles of experiential facilitation and factor axes (i.e., Factors 1 and 3 ) that involved igniting a local spirit of environmental justice.

Pragmatically, the important lay epistemic theory underlying these results assumes much of situated and mediated social interaction is governed by the way students process information to form subjective knowledge from how the information is delivered. For instance, in this riverine realm, stream discharge calculation processes were found to affect each UCN student's tendency to exhibit construct-accessibility effects while interpreting local ecological measurement related to their own abilities. Moreover, while conducting social comparisons with those unwilling to have their knowledge confronted, inductive frameworks of overt behavior were socially 'checked' contextually, perhaps contributing to psychological phenomena from a motivating social cognition perspective. Students resultantly acted depending on how their in-situ and overt responses were assessed by others in the cohort.

At a coarse evaluative level, candidates realized a simple multiple-choice request and answered appropriately (i.e., Factor 2). However, it was more useful to review composite learning in a refined manner while assessing long answer questions and mathematical calculations with digitally quantified latent statements (Factors 1 and 3). Participatory video and EFA provided this insight on a heightened level of scholastic inspection to operationalize north-sensitive constructs (i.e., extras) in statements that could be evaluated meaningfully. As posited by Atleo (2001), this mixed exploration and examination of situate processing required UCN learners to 'move through several levels of analysis in the development of metaphoric blends which weave native and non-native worlds together' (p. 37).

In a direct response to Lunch (2008) and his report that video has an ability to 'help other methods go even further', this UCN use of PV not only advances qualitative methodologies, but certainly quantitative and mixed approaches to assessment in environmental learning as well. Rosenstein (2008) likewise forwards how PV assists in pushing for change by incorporating similar ideas for erudition, discussing an exceptional use of 'participatory video training, education and action' within Proshika's forest destruction in Bangladesh. In similar fashion, Stewart, Riecken, Scott, Tanaka and Riecken (2008) cite a PV clip created in less than three hours that was effective as an advocacy tool for women's rights. Conversely, and although Day and Baskett (1982) show experiential contexts are frequently shunned institutionally by "problems in matching states of learning readiness to course content and learning process" (p. 149), these UCN student results indicate an alternative perspective and paradigm be entertained, a method launching visual rubrics for student assessment into the contextual North. 
In sum, and as an epistemological epilogue to the use of EFA in this ethnosemantic PV approach, I close with the observation that educational design and delivery has made little use of visual technologies for student assessment. It seems to me that in an epistemological and phenomenological sense, PV used in this UCN procedure has revealed surprising potential. Educationally, analytical endeavors without PV seem wasteful given the connection between lesson delivery and expected graduate aptitudes regarding sustainable survival. I suggest educational researchers find this PV process and ethnosemantic examination both instructive and sophisticated for tackling epistemological, scholastic and axiological challenges of remote-based student learning. Needed are heuristic lesson experiences and associated assessments to counter-balance imported and urbanized didactic archetypes, strengthening northern learner confidence in local understanding and accomplishment.

\subsection{Four-Level Model Conceptualization}

\subsubsection{Level 1: Being Collaboratively Situated}

Yet discussed are conceptualizations forwarded as a hierarchical model for remote-based student learning. As with all training philosophies, implementation of applied curricula have limitations including the fact experiential programs are time-consuming to develop and needful of intrinsically motivated learners (Hung \& Chen, 2000). In pact with Lunce (2006) however, these perspectives are unfortunate as everyday cognition in situated arenas is not only well suited to solving problems and transferring secure base level knowledge, but like these UCN findings, indicate experiential 'situate facilitation' pronounces a positive academic influence is possible. Besides reducing the time required to relay instream discharge-calculation skill-competencies from 90 to 15-minutes, collective nonconventional lesson delivery and assessment were well suited to place-promoting empirical and behavioral advance. Viewing blended results from the perspective of intellectualizing a theoretical framework, this in-situ stream exercise and base level platform, proved foundational with student novitiates from all seven programs.

For two-thirds of these students, there were academically improved aspects involved with the richness of this shortterm exercise that resonated with each open-ended interview appraisal and composite test score, as well as with each participant's relationship to local environment. Gee (2010) similarly documented affinities between being situated and the creation of 'new literacy understandings' that individuals acquire through experience and 'being in the moment'. Although scholastic dimensions are under-theorized, Greeno (1994) and Barab and Roth (2006) provide early expositions of how situate-knowing has 'positive learning attractions' co-determined by engaged participants and a contextualized base setting. For Lave and Wenger (1991), it is not just a matter of arriving at a single multiple-choice answer - it is about having a learner arrive at a place-relevant and emerging stance, competently and attitudinally.

Remarkably, it has been a century since Spearman (1927) first defined Gee's (2010) contemporary meaning of a 'new literacy', positing the capacity to identify and solve in-situ challenges depends on a simultaneous understanding of the 'whole' and knowing which incoming stimuli may be ignored, in lecture and life. Nideffer (2002), as well, suggested concentration shifts along competing dimensions related to very narrow and broad foci simultaneously. That said, to be academically effective, students must be able to shift their concentration in response to the changing demands of any complex learning experience when placed in the middle of it. This ability to squeeze concentrated insight involves making new meaning from confusion to forge significance probed by concerted exchange during the lesson, going beyond the traditional pedagogy of 'exposition and drill' (Simkin \& Kuechler, 2005).

Expressed by one UCN student, "I guess for me, you know, it's just a consistent anxiety for me with anything new. I always wonder, ok, how will I measure up to others because sometimes it comes as a rude surprise when you think you are going to do well at something and find out you are the worst in the class. With this one [exercise], I really thought I wouldn't get on with it. I thought I might be the worst in the class, and sometimes you think that and you really are. This time I thought I might be, and I wasn't". For Mezirow (2000, p. 7), this unsolicited and typifying response reflects an engaged participant 'transforming' taken-for-granted frames of reference in order to make them "more inclusive, discriminating, emotional ... and reflective so they may generate opinions"; effectively a new 'belief frame' with a foundational reference I posit will guide future scholastic advance and social action of 96 other northern UCN participants. The alternative is an unthinkable subset of UCN graduates who are close-minded to sustainability.

Additionally crucial to this hermeneutic frame of mixed worth, was being judgmentally challenged by deviate opinions within the working cohort to consider alternative ways of thinking and behaving (Gardner, 1991). Assumed proportionate to perceived benefits, labors of information processing, time pressures, and perhaps even escaping some other unpleasant activity, supportive reflection with these participants was 'anchored' in an applied communal experience. Collins and Brown (1988) and Mezirow (2000, p. 22) too, hold adult learners must move 
through a series of 'meaning phases' to undergo development from disorienting dilemmas in order to unite situate 'awareness' into reintegrated life experience and ultimate social opinions. Theoretically, high desires for skill level competency and affective comfort are deemed essential for 'success' in lay epistemic reality. Each reflected in the decisiveness of judgment and choices pertaining to a desire for secure knowledge. A 'secure' knowledge is one that can be relied on across circumstances and is unchallenged by exceptions or disagreement; a trans-situationalconsistency affording predictability to future contexts (McLean, 2013).

The Situational Model of Hersey and Blanchard (1982) recognizes this comparable 'self-assessment' depends on not only the 'classroom seated' individual, but also the social situation. Their model equally considers participant ability, motivation, performance and feedback in facilitating understanding in personal, intellectual and affective growth circumstances. Hence, in viewing this concerted streamside 'ceremony' from foundation to selfactualization, every UCN student interacted with each other and the environment in some way, determining what affordances were available to ground 'their' new 'effectivities' and consensual needs.

Shaw, Turvey and Mace (1982) first introduced the term 'effectivities' as the ability of a participant to determine what they 'could' do. Newman (2010, p. 14) submitted such feedback is "good learning"; a reworked consciousness along Freire's notion of 'conscientization'. Interestingly, for knowledge to be secure, Garland (1992) submitted "it appears that natural resource scientists could more effectively share their knowledge if they simplified it, assumed no prior understandings, and helped people learn by informally and subjectively putting it in a more holistic context for them, including making inferences to application and implication" (p. iii). These associative UCN base level scholastic findings demonstrate this first platform's ability to discriminate between groups of students for whom a difference in lesson transfer and a dispositional need for situationally induced behavior plausibly exists.

\subsubsection{Level 2: Developing Awareness and Quale}

Following the in-stream exercise being situated and providing the opportunity to share at a base level of practice, participation provided not only for a new 'awareness', but a fresh potential for some elevated affective level of subjective consciousness. By definition, 'awareness' was considered the ability to perceive or be conscious of events and patterns culminating in a new and established mindfulness. Contrariwise, 'awareness' may also be focused on an internal state where it provides the raw material for a visceral feeling, a personal and culturally subjective 'aha moment' from which participants develop transformative ideas about their private experiences while participating.

My defense for incorporating this construct is that this possibility for non-physical dimensions of learning have been foregrounded in the literature for decades. For instance, Nagel (1974, p. 437) claimed that being situated and conscious has a subjective character, a "what is it like" aspect, a mental state which is insufficiently accounted for by strict objective evaluation. Jackson (1982) also offered 'something more' exists, and if true, participants acquire knowledge, ability and a particular 'wow' they did not possess before. This 'transformation' Jackson argues, is a quale. McDowell (1998, p. 42) defined this 'awareness' as a "raw feel" or "bare presence"; a perceptual involvement where description is impossible to convey verbally regarding certain perceptual experiences for which no account of purely physical information exists. And, since there are differences between those who have access to a ' $w o w$ ' and those who do not, it was conceded qualia must be real and were therefore considered operationally in this UCN student investigation.

Lewis (1929) was the first to use the term qualia, but Schrodinger (cited in Moore, 1992) described quale as "an intrinsic subjective experience that does not form a one-to-one correspondence with stimuli" (p. 14). Dissecting definition further, Dennett (1991) pronounced 'properties' of qualia include the notions they are: 1) ineffable and thus incommunicable by means other than direct experience; 2) intrinsic and thus unchanging; 3) a private rendering making comparisons impossible; and 4) apprehensible. In essence, to experience a quale is to know that one experiences it.

Philosophically, the term quale refers to apprehending something so transformative that it can existentially cleave a participant's mind. James (1961) described this panoramic clarity as a snap-resolution of the 'divided self'. For instance, and introspectively, a 'quale' is a monadic and qualitative feature such as the sound of my departed Dad's voice asking if I had time for coffee from a saved nine-year old phone message ... and what it means to me to hear it now. Lycan (2001) summed such abstract meaning as a qualitative collection of sensory experiences, while Dennett (2005) wrote quale is an 'unfamiliar term for something that could not be more familiar to each of us: simply, the way things seem to us'.

Irrespective of criticisms that articulate information and ability as two different things Kovan and Dirkx (2003) suggest metaphysical moments are ancient and necessary for survival. And, although Henderson (1956) discussed 
Jungian psychology and its educational significance more than a half-century ago, the role in active evaluation of qualitative constructs, including behavioral transformation in adult learning, have been inconspicuous in Manitoba's North. Subsequently, in pursuing behavioral change related to non-conventional lesson delivery, I considered these extra-rational perspectives forwarded by unsolicited UCN student statements incorporating the possibility of their existence into integrated 'academic' assessment.

Building on the lack of documented analysis in extra-rational design, I offer this second level in a meta-cognitive framework for a 'fair-er' consideration in an evaluative postsecondary methodology. Necessarily, my model and mixed strategy rests on both empirical testing and quantified insights from student experience. Since definition of these blended metaphysical possibilities are difficult to convey, I forward the tangential UCN student finding; that 65 of 97 (70\%) unsolicited video-recorded responses reflected some level of 'qualia', indicating they are pervasive and undeniably important when related to academic achievement.

Conferring importance, Kucukaydin and Cranton (2012) raised particularly interesting questions regarding strategic approaches to education using emotionally charged and disorienting dilemmas as lesson catalysts. Van den Noortgaete (2015) concurs suggesting transformative identity involves emotional and spiritually intrinsic value beyond utility with paramount connections to nature and social justice. In the absence of 'direct' proof, these mixed UCN student results offer interesting academic considerations that suggest constructs of quale are not only scholastically assessable, but their integration into transformative curricula is empirically possible to index and ponder.

Hierarchically, these second-level platform findings reflect days in the stream where each UCN student had the opportunity to create subjective ideas from participating collaboratively while being exposed to the environment and principles associated with the competency of skill and knowledge procurement. Empiricalized results indicate in-stream experiences, inclusive of didactic and situated deliveries, 'catapulted' participant need from a reserved 'awareness' to intentional or motivated 'knowledge and/or skill' verbalizations (Model level 3). By participating in non-traditional practice designed to reinforce the tenets of replacement, reduction, refinement and sustainable development (Russell \& Burch, 1959), a more comprehensive evidence on which to base a decision about 'value judgments and graduate aptitude' (i.e., designed to predict success in some 'future' activity) is forwarded. Recall, learning outcomes using these ubiquitous domains emphasize 'representative' responses rather than a high testscore or GPA, an authentic outcome inclusive of interest, attitude and place-sensitive personal to social progress.

\subsubsection{Level 3: An Intrinsic Desire for Knowledge and Skill}

Following the stream activity being situated and collaborative (Model level 1), and the idea participation provided an increased opportunity for 'awareness' and the possibility for an elevated raw-feel 'quale' (Model level 2), the generation and assessment of new knowledge (necessary for understanding-NFU) and/or skill competency (mandatory for procedure-MFP) were examined in Stepaniuk (2019). Employability skills and knowledge were defined here and previously as transferable abilities, along with some technical understanding of subject knowledge, technical equipment expertise, and mindset increasingly necessary in the modern workspace (Lew \& Hardt, 2011). These employability pre-requisites are considered essential qualifications for many resource management positions in northern Manitoba and hence ascribed necessary for regional success while simultaneously reducing the 'notion of failure'.

As one goal of environmental education is to build an understanding of scientific systems of ecology that frame the nature of environmental challenges and their possible solutions (Kahn, 2008), educational scholars support the idea of a 'curriculum for ecology in which ecological problems become educational problems' (McLean, 2013). Unfortunately, unless the dominant narrative of didactic lesson distribution is disrupted, outdoor education in northern Manitoba is problematically positioned, as the way UCN has been trying to ambassador and preserve each student has been ecologically insufficient.

\subsubsection{Level 4: Overt Behavioral Transformation}

Following the stream activity being situated (Level 1), providing opportunities for elevated 'awareness' (Level 2), and an intrinsic desire for in-situ skill acquisition (Level 3), there was an opportunity for each UCN student to experience an intermediary 'intention' considered here as a recipient's location on a subjective dimensional continuum involving any preparatory relation to a 'measurable' act. In this respect, an intention refers to the possibility a student executes an overt deed which is captured digitally. Operationally, the more favorable a student's intent (e.g., attitude towards lesson type), the greater the possibility for achieving, displaying and documenting a scholastic and transformational change.

Recognizing an operational need for greater specificity and clarity in selective coding, transformation assessed in 
these data refer only to a manifest gesture culminating in a digitally-captured overt response or act (Model Level 4). For instance, one UCN informant described it this way: "It opened my eyes. Like, I don't really know how to explain it but I have changed. Like, I've started recycling and before I just didn't care because it is just going to go to the dump anyways. I pick up garbage now. Before this research, I didn't care because when we were there in the water, we found keys and glasses and like it's our drinking water. We don't want to be drinking stuff like that in our water. It changed me".

Succeeding Mezirow's (2009) lack of attention to context and exclusion of 'other ways of knowing', the participant's conceptualization immediately above makes for a 'better-informed' phenomenological positioning to theorize long-standing misapprehensions regarding low GPA and graduation rates in northern Manitoba. With this alternative form of scientific literacy in mind, it is important to note exploratory factor axes indicate scholastic performance is not simply cognitive, but affective components inextricably linked to life values and agentic experiences were of academic worth (i.e., Factor 1 and 3). Results show there $i s$ space for a caring conversation regarding freshwater sustainability and a genuinely inclusive evaluative system using non-traditional lesson delivery.

Likely as germane to northern Manitoba as Sierra Leone, Kanu (2011, p. 215) presented a similar need to integrate "knowledge that balances the strength of Aboriginal peoples with the problems they face". A balanced delivery or 'currere' catalyzed using emotional dilemmas that provoke a shift in understanding of ecological consciousness and conscience (Walter, 2013). As Jarvis (2005) suggests, self-directed learners often "need to make situated and sometimes lateral, emotional and intuitive decisions about the best course of action" (p. 44). Interestingly, these empirical-ized UCN findings emphasize how affective 'tipping points' foster critical learning and identity development in enrollees. Of $65 \mathrm{UCN}$ students that experienced 'something more', 36 unsolicited responses reflected some empirical-ized measure of environment-related behavior change. That is, almost $70 \%$ of those students who referred to extra-rational moments signaled a promoted scholastic advance related directly to some form of overt freshwater advocacy. Mixed assessment of these UCN students was crucial to this understanding.

\section{Implications for UCN and Northern Manitoba}

In the results, I introduced methods and methodology conceptualized to tap student differences in motivation merged from scholastic confirmation and quantified associative overt displays of environmental advocacy. I first began by presenting quantitative evidence regarding scholastic test score properties related to four divergent lesson styles (Stepaniuk, 2019). Next, clustered and quantified qualitative ancillary factor data from the four different lesson deliveries using the identical 97 student subjects suggested a place-responsive four-level hierarchical model possessed a factor and axes structure consistent with the theoretical expectations forwarded.

Recall, to describe dimensions of individual differences related to information processing, unsolicited student statements were treated as latent and private manifestations of situatedness and an engaging attitudinal desire for knowledge and skills acquisition. The abovementioned results suggest the development of this hierarchical model offers four distinct advantages. First, it affords a cross validation of lesson deliveries and test scores, as theoretically, students who scored high should exhibit similar patterns. This comparison of composite test scores from didactic versus situated induction represent an examination of at least the 'need' for exploring associative behavioral constructs. Effectively, PV and model development permitted a richer exploration of the associated unsolicited subjective expressions of new learners. That is, construction of a specific activity and 'set of lesson deliveries' afforded the opportunity for a differentiated conceptualization of ways in which the need for anticipated graduate aptitudes may be supportively examined in the north. In sum, a mixed design offers this superb opportunity for place-sensitive curricular and theoretical refinement.

Second, a situated exercise and hermeneutic comprehension of individual student performance enabled documentation, review and allocation of novitiate response variances to be categorized enhancing the statistical power for assessing instructional effects. This event-driven process consists of four levels that allow construct relationships to progress as active events depending on lesson flow; each level with an ability to transform events and link to another level-driven process, all of which work together to define how non-Likert derived responses represent behavioral sophistication - a simplified but abstract view of a complex learning reality. Model intent therefore, has wide application in the building of information to support activities involving students and events in northern Manitoba. Successively, my goal was to convey the basic functionality of this four-level system in satisfying three objectives: 1) to facilitate an effective conveyance of hierarchical detail between model levels; 2) to provide a point of reference for facilitators in remote locales to consider and extract blended evaluative specifications; and 3) to document a conceptual model providing a means to better assess transformative student personas in remote educational environs. 
Third, further validation will derive from evidence that each conceptualized platform significantly discriminated between unsolicited but normalized candidate response-clusters. Hence, a particularly important form of validation will be in student replications obtained through other diverse program assessments. My study has also demonstrated primacy in environmental sustainability impression formations that are stronger for students in situational settings. It is precisely this theoretical framework, that lends unique significance to northern research and ideologies, assuming student judgments contain a motivational component arising from not only personality dispositions, but contextual influences while apprenticing in new skill development. It is this theoretical feature that uniquely warranted my comparison of different lesson manipulations for determining motivational significance and the results attained. Methodologically, PV used as an ethnos-science provided this categorical technique and repeatedly accessible digitized repository for remote student co-development grounded in local motivation.

Going forward, valid and reliable measures of overt behavior offered in this UCN study will contribute to the development of a supplementary educational DVD visually exhibiting merged scholastic performance 'and' behavioral goodness related to local freshwater sustainability. Moreover, from these lesson findings and the use of a regionally appropriate technology, 'awareness' enhanced through place-based instructional 'add-ons' and engaging workshop excursions, will no doubt propel consciousness and intensify efficacy of academic advance and overt behavior. With a great deal to offer, the integration of a PV process and allied phenomenological response into academic measures will allow UCN to: 1) sense local conscience in consumptive practices; 2) avoid category mistakes (Ryle, 1971) in worldview counter transfer; and 3) adapt accordingly in post-Covid environments. Ardently, a better job of training remote-based students to meet obscure freshwater dilemmas in northern community sustainability is required.

\section{Autobiographical Reflection}

As a final point, and in autobiographical reflection, my research findings indicate environmental advocacy is indeed measureable in lesson design. In a narrative sense, the ability to effectively pattern problematization within a caring situation is what I now refer to as being able to traverse ... 'Gord's Gap'. It is within this simple phrase I metaphorically use a late autumn mid-morning experience to present the implications of my research and the practical meaning it has for lesson transfer related to remote student assessment.

Imagine a two-hour road trip north of the UCN campus to measure boreal stream flow as a situated class exercise. Our group consisted of 17 students, my father Gordon Stepaniuk and myself. Following the morning's drive, we all stepped out of rented passenger vans into the cold and started down a 500-metre riparian footpath, navigating through an almost unlit Picea mariana forest. Within 300 meters or so, I was shocked by how a change in early morning weather had darkened everything. Once in this boreal canopy, only random sunrays illuminated my father who was leading the procession. Passing glances at him showed his seventy-plus years, but his eyes were dancing. Age had forgotten him as he arrived at the stream-edge first.

As all good writing is in some way an act of remembering, I was glad my dad was using his day to lobby for my research, but as I ambled down the streambank behind him I saw he was bent at the waist with his arm-outstretched, tapping a frozen river surface. Ice blanketed the small stream. To break the following silence that hung between us, my Dad stated ... "nuff said". I felt instantly uninformed. I struggled to reshape my understanding of the situation now facing me as the students began to huddle around us. My mind went in unhelpful directions. I was uncomfortable as a facilitator and in a free-floating anxiety. How did the stream freeze so quickly? What was I to do with these students now?

Only hours before, my plan was to be standing in a 'flowing' stream interacting with 17 eager participants. I had hoped to be inhaling the autumn's senescence, perhaps laughing with my Dad as these new enrollees stumbled over slippery rocks wearing a pair of rubber pants. Unfortunately, Wisakedjak chose to challenge my timing and perception for lesson delivery, creating and then limiting what Mezirow $(1990$, p. 2) so appropriately refers to as the "habit of expectation".

The silent return to UCN that same morning without having facilitated the on-site lesson demonstration was oppressive. As I watched the forest pass through the passenger window returning to campus, I questioned what the students had experienced ... if anything. What I should have been doing was 'watching' my father's mind. Where I was experiencing nothing but a traumatic humiliation and cerebral ' $g a p$ ' ... my Dad was 'problem solving' wildly.

According to Dennett (1991), the most salient fact about 'conscious experience' is that when a cognizant being is experiencing, they are capable of forming reasonable and mature judgments. Unfortunately, a frozen river and the relative abject failure of my intended lesson plan 'impaired' my judgment. Regrettably, I was utterly out of touch with my father's conscious experience while sitting only inches away from his wisdom. As a Natural Resources 
Management Technology (NRMT) facilitator for more than two decades, I was sitting in the returning passenger van and metaphorically letting the faucet run.

Nonetheless, woven through this experience is a theme narrated by my Dad's ability to problem-solve and traverse a meta-cognitive gap. In the evening that followed, and because it was impossible to measure streamflow at the intended site with this remaining group of students, my father's excitement and my anxiety pooled to create an alternate model for facilitating the botched stream exercise earlier that day. Bearing on his shoulders the welfare of his son, my Dad offhandedly suggested using a rotating variable-speed 'house fan' that could possibly mimic river flow when pointed at the stainless steel velocity meter. Brilliance.

Later that evening, we were together creating benthic relief to portray a reasonable range of fluvial characteristics using that house fan to circulate 'air' (rather than water) through the Price No. 622 Type AA current meter supported by an assortment of boxes, a plastic pail, soup cans and a roll of packing tape. Variable times and premeasured distances between the fan and current meter were fashioned so mock flow characteristics were mimicked demonstrating variable stream velocities, the effects of backwaters, unstable flow features, and a diversity of currents that provide important elements of boreal aquatic habitat. It was looking as though the technical prowess demanded of the student participants could soon be assessed.

Hours later, our idea would be to artificially portray the stream process 'in a classroom', salvaging the previous lesson's expectations while permitting the understanding of complex concepts that had been inaccessible the day before. Wearing toques and chest waders (in the classroom) convinced students that assessing stream flow was fun, interesting and essential in knowing how to better manage this precious 'resource'. Both pseudo-fluvial processes and cooperative alliances were observed over a surprisingly short period-of-time. Regardless of the previous day's catastrophe, our model fascinated participants from this last student cohort.

Looking back ... my Dad was in a life phase when contributing was no longer just being a part of something, but a means to 'understand'. In that awkward lesson transfer situation, my father was able to perceive a 'gestalt' and juggle inter-variable relationships within some extra-ordinary space, or 'in-betweeness' to help bridge a son's challenge ... to overcome a facilitative, intellectual and perhaps affective ' $g a p$ '. There is still a vibrancy to these last days in my memory and I thank him for reminding me of something countless classroom sessions could not ... to 'problematize'.

Woven into this homage is a 'frame dragging' and haunting 'Lense-Thirring' subtext of my father's ability to perceive and coach me even now, from 'somewhere' inside a Minkowski-space based on his life experiences and most certainly the fact he was an external and caring companion. In effect, my 'perceived' catastrophic situation of having to facilitate a place-based lesson in light of a bewildering icy challenge required a new and particular 'intention' that was then invisible to me. Like the evidence of a concave water surface in Newton's stilled bucket, the effect of my Dad in this universe still exists ... an inertia originating in a kind of interaction between bodies ... between "matter there influencing inertia here" ... somehow flowing from inner sources beyond the reach of instruction (Bondi \& Samuel, 1996, p.121).

Most important to me now, is that a post-situate solution to an expression of an existing challenge was altered directionally by varying relevant aspects of the initially perceived learning reality and the relationships for each of the now 19 participants involved. Interestingly, in the course of student testing and 'data' coding of normalized and unsolicited PV interview offerings in the weeks that followed, most of the students seemed perfectly sensible in their beliefs about the stream discharge calculation experience - even though these 17 students had never actually waded in a northern boreal stream. Unlike the previous 80 students that had participated in the 'in-field' activity, this remaining group's ontological assumptions demonstrated an epistemological shift - from stream situativity to 'classroom', suggesting a pedantic model that applied 'thinking on the fly' was in some ways no different from the intended in-situ experience.

In essence, active cognition 'was not' separated from 'context'. Instead, problem solving and 'knowing' existed in-situ, using imagination and a house fan on the classroom floor while being separated from ecological and 'stream-side' context. Methodologically, problematizing for these remaining students was perceived in terms of an effective performance across sites 200 kilometers apart, but later co-determined by ' 19 students' (including my dad and I) and two completely different contextual environments. Unbelievably, I could not empirically point to any unusually poor insights or inferences among these students and their unsolicited interview responses compared to those 80 individuals who had experienced the in-stream lesson delivery in its fullness.

As Ellsworth (2005) professes, the most powerful learning experiences arise from public pedagogies that emphasize non-cognitive events. For her, my father, and apparently these 17 students, critical learning does not occur in straightforward, rational nor linear ways as I had so initially planned. Ellsworth explains that new ways 
of seeing a 'challenging world' can be released only through movement into (and within) messy intervals of space and time ... between 'things' we already know and between 'beings' we perceive of ourselves and others. She states this in-between 'is the gap' where personal and social transformations occur. I now believe this 'in-betweenness' is a metonym for a vision of being an 'adult learner' and a facilitator, developing an identity and organizing one's own self-advance. This is precisely what I witnessed post-lesson catastrophe, observing my father traverse an intellectual gap ... Gord's Gap.

In contrast to the rigid intentions and benefits of Lave and Wenger's (1991) legitimate peripheral participation (LPP), Ellsworth suggests this gap or in-betweeness - and moving away from cohesion and unity - is what constitutes where learning and 'knowing' flow freely. From her perspective, knowledge acquisition is a 'relational' practice, first disrupted and then rebuilt for those engaged, consisting of "experiences radically in relation to one's self, to others, and to the world" (p. 2). Operationally then, my initial and disturbing streamside assumptions could surely have focused more on the embodied, holistic and aesthetic aspects of real student learning. I now see problematization, transformation and critical knowledge acquisition as more 'tentative and ambiguous' following working alongside my Dad.

Seemingly, for both my father and Ellsworth, the dimensions of learning that occurred that autumn day, did so in the hard to define 'in-between' spaces traversing 'Gord's Gap' ... placing himself, the students, society and a son's altered lesson plan in relationship with one another. In accordance with Lather (2004), it was through this precise process of getting lost that interesting learning started for each of us. These transitional spaces begin where knowing is incomplete and unfinished. I now firmly believe it is in such powerful situations that we set ourselves in motion towards some open future for behaving sustainably.

Following my initial and 'failed' lesson experience, I truly believe blended techniques for constitutive learning are ontologically subjective and are only accessed by an engaged learner - while in 'some' context. I have no doubt this kind of knowledge is open to creative questioning and further research in the context of remote-based adult lesson delivery and assessment. Regrettably, such concepts do pose challenges in reaching academic and scholastic consensus as any attempt at explanation must use 'other' unknowns, requiring some level of unconditional acceptance and exploratory examination, reaching to meet student 'constructs' where they are positioned.

In defense of my search for empirically documenting 'extra-rational' constructs and using exploratory factor analysis to search associations, these results show that UCN student ideas seeped from 'their' in situ evaluation of thoughts and unexpected insights, linking them across 'raw feel' gaps in 'awareness', through knowledge and skill acquisition to personal advocacy in a deliberate manner (McDowell, 1998, p. 42). Although described as mystical 'things-in-themselves' (Lewis, 1929), Miller (2001) noted situate 'qualia' can be a fast-forward in selfactualization: conscious triggers originating from intense psychological pressure. Excitingly, the moment such epiphanies do happen recipients know they have gone through a one-way door to understanding. Sandlin et al. (2011) considers this advancement in learning, a gap negotiation towards overt behavior change and subsequently improved scholastic understanding. Notably, Figueredo, de Baca and Woodley (2013) recognized not a single recipient returns to their pre-epiphany ways even decades later. Thus recipient 'values' change irrevocably.

Stimulatingly, Kripke (1971) claimed a consequence of quale even existing, leads to the possibility of a student recipient capable of intentional thought extension crossing construct gaps to advance personal behavior. Similarly, Van den Noortgaete (2015) too, suggests holistic processes inclusive of transformative learning involve human emotional and spiritual identity, intrinsic value beyond utility, and some connection to nature and social justice. And although Henderson (1956) discussed this same educational significance based on lesson design more than a half-century ago, the role of qualitative constructs in active evaluation including behaviors within adult learning have remained neglected.

In building upon an apparent lack of critical literature related to my search for an extra-rational approach to affective evaluation, improved scholastics and labeling of adult learners, I offer researched data, an applied conceptual framework, and a 'personal story' for consideration and critique. As Jarvis (2005) suggests, selfdirected learners often need to make in-situ and sometimes lateral, emotional and intuitive decisions about the best course of action. Hence, my focus was on how place-sensitive environmental epiphanies might foster critical learning and self-identity in northern students. Recall, 65 of 97 candidates coded themselves as being recipients of quale while 36 provided verbal evidence of an overt behavioral change; that is, approximately $70 \%$ of those who mentioned an 'aha moment', unsolicitedly indicated to an earthly behavioral 'awareness' related to some form of local and overt freshwater advocacy. All told, having this last opportunity to work alongside my Dad solidified the significance of such learning experiences for me. 


\section{References}

Adult Learning Literacy and Essential Skills Program. (2016). Retrieved from http://www.acronymfinder. com/Adult-Learning-Literacy-and-Essential-Skills-Program-(Canada)-(ALLESP).html

Anderson, J. R., Reder, L. M., \& Simon, H. A. (1996). Situated learning and education. Educational researcher, 25(4), 5-11. https://doi.org/10.3102/0013189X025004005

Andrich, D., \& Styles, I. (1994). Psychometric evidence of intellectual growth spurts in early adolescence. The Journal of Early Adolescence, 14(3), 328-344. https://doi.org/10.1177/0272431694014003002

Arghode, V., Brieger, E. W., \& McLean, G. N. (2017). Adult learning theories: implications for online instruction. European Journal of Training and Development. https://doi.org/10.1108/EJTD-02-2017-0014

Atleo, M. R. (2001). Learning models in the Umeek Narratives: identifying an educational framework through storywork with First Nations elders.

Atleo, M. R. (2008). Watching to see until it becomes clear to you: Metaphorical mapping - a method for emergence. International Journal of Qualitative Studies in Education, 21(3), 221-233. https://doi.org/10.1080/09518390801998338

Bandura, A. (1977). Social learning theory. Englewood Cliffs, NJ: Prentice-Hall.

Banyard, V. L., \& Graham-Bermann, S. A. (1993). A gender analysis of theories of coping with stress. Psychology of women quarterly, 17(3), 303-318. https://doi.org/10.1111/j.1471-6402.1993.tb00489.x

Barab, S. A., \& Roth, W. M. (2006). Curriculum-based ecosystems: Supporting knowing from an ecological perspective. Educational Researcher, 35(5), 3-13. https://doi.org/10.3102/0013189X035005003

Bateson, G., \& Mead, M. (1942). Balinese character: A photographic analysis. New York, 17-92.

Bauman, Z., \& Bauman, Z. (1993). Postmodern ethics.

Berelson, B. (1952). Content analysis in communication research.

Bligh, D. A. (1972). What's the use of lectures? Harmondsworth, Mdx.: Penguin Books.

Bocking, S. (2005). Scientists and evolving perceptions of indigenous knowledge in northern Canada. Walking a tightrope: Aboriginal people and their representations, 215-247.

Bondi, H., \& Samuel, J. (1997). The Lense-Thirring effect and Mach's principle. Physics Letters A, 228(3), 121126. https://doi.org/10.1016/S0375-9601(97)00117-5

Brownell, P. (2010). Gestalt therapy: A guide to contemporary practice. Springer Publishing Company.

Chase, S. E. (2005). Narrative inquiry: Multiple lenses, approaches, and voices. In N. Denzin, \& Y. Lincoln (Eds.), The Sage Handbook of Qualitative Research, 3 (pp. 651-679). Thousand Oaks, CA: Sage Publications.

Chowdhury, A. H., Hambly Odame, H., \& Leeuwis, C. (2014). Transforming the roles of a public extension agency to strengthen innovation: Lessons from the national agricultural extension project in Bangladesh. The Journal of Agricultural Education and Extension, 20(1), 7-25. https://doi.org/10.1080/1389224X.2013.803990

Cody, R. P., \& Smith, J. K. (2005). Applied statistics and the SAS programming language. Elsevier North-Holland, Inc.

Colaizzi, P. F. (1978). Psychological research as the phenomenologist views it.

Collins, A., \& Brown, J. S. (1988). The computer as a tool for learning through reflection, 1-18. Springer US. https://doi.org/10.1007/978-1-4684-6350-7_1

Comrey, A. L., \& Lee, H. B. (1992). Interpretation and application of factor analytic results. Comrey AL, Lee HB. A first course in factor analysis, 2.

Cortazzi, M. (1993). Narrative analysis. Social Research.

Cottrell, M. (2010). Indigenous education in comparative perspective: Global opportunities for reimagining schools. International Journal for Cross-Disciplinary Subjects in Education, 1(4), 223-227. https://doi.org/ 10.20533/ijcdse.2042.6364.2010.0031

Creswell, J. W. (2007). Qualitative inquiry and research design: Choosing among five approaches. Thousand Oaks: Sage Publications.

Day, C., \& Baskett, H. K. (1982). Discrepancies between intentions and practice: re-examining some basic assumptions about adult and continuing professional education. International journal of lifelong education, 
1(2), 143-155. https://doi.org/10.1080/0260137820010205

Dennett, D. (1991). Consciousness explained. Boston, MA: Little Brown.

Dennett, D. (2005). Sweet dreams: Philosophical obstacles to a science of consciousness. MIT press. https://doi.org/10.7551/mitpress/6576.001.0001

Dewey, J. (1938). Experience and education. New York: Collier Books.

Diep, A. N., Zhu, C., Cocquyt, C., De Greef, M., Vo, M. H., \& Vanwing, T. (2019). Adult Learners' Needs in Online and Blended Learning. Australian Journal of Adult Learning, 59(2), 223-253.

Ellsworth, E. (2005). Places of learning: Media, architecture, pedagogy. Routledge. https://doi.org/10.4324/ 9780203020920

Emmeche, C. (1997). Defining life, explaining emergence. Retrieved from http://www.nbi.dk/ emmeche /cePubl/97e.defLife.v3f.html

Fetterman, D. M. (1998). Ethnography.

Figueredo, A. J., de Baca, T. C., \& Woodley, M. A. (2013). The measurement of human life history strategy. Personality and Individual Differences, 55(3), 251-255. https://doi.org/10.4324/9780203020920

Firth, R. (1973). Hair as private asset and public symbol. Symbols public and private, 262-298.

Fraser, S. P. (2015). Transformative science teaching in higher education. Journal of Transformative Education, 13(2), 140-160. https://doi.org/10.1177/1541344615571417

Gardner, J. W. (1991). Building community. Washington, DC: Independent Sector.

Garfinkel, H., Lynch, M., \& Livingston, E. (1981). I. 1 The Work of a Discovering Science Construed with Materials from the Optically Discovered Pulsar. Philosophy of the social sciences, 11(2), 131-158. https://doi.org/10.1177/004839318101100202

Garland, M. R. (1992). Variables affecting persistence in distance education in the natural resource sciences (Doctoral dissertation, University of British Columbia).

Gee, J. P. (2010). New digital media and learning as an emerging area and "worked examples" as one way forward. Cambridge, MA: MIT Press. https://doi.org/10.7551/mitpress/8563.001.0001

Geertz, C. (1973). Thick description: Toward an interpretive theory of culture. Turning points in qualitative research: Tying knots in a handkerchief, 3, 143-168.

Gibson, E. J. (1966). Perceptual learning in educational situations.

Glesne, C., \& Peshkin, A. (1992). Becoming qualitative researchers: An introduction. White Plains, NY: Longman.

Goodenough, W. H. (1957). Cultural anthropology and linguistics. Bobbs-Merrill.

Gough, S. (2005). Rethinking the natural capital metaphor: Implications for education and learning. Environmental Education Research, 11(1), 95-114. https://doi.org/10.1080/1350462042000328776

Greeno, J. G. (1994). Gibson's affordances. https://doi.org/10.1037/0033-295X.101.2.336

Henderson, J. L. (1956). Jung's analytical psychology and its significance for education in the light of recent literature. International Review of Education, 2(3), 368-372. https://doi.org/10.1007/BF01416640

Hersey, P., \& Blanchard, K. H. (1982). Leadership style: Attitudes and behaviors.

Howley, K. (2005). Community media: People, places, and communication technologies. Cambridge University Press. https://doi.org/10.1017/CBO9780511489020

Hung, D. W., \& Chen, D. T. (2000). Appropriating and negotiating knowledge: Technologies for a community of learners. Educational Technology, 40(3), 29-32.

Husserl, E. (2012). Ideas: General introduction to pure phenomenology. Routledge. https://doi.org/10.4324 /9780203120330

Indian and Northern Affairs Canada [INAC]. (1997). Survey of First Nations People Living Off-Reserve, Metis and Inuit. Retrieved from, http://knet.ca/documents/OFF_RESERVE_SURVEY_E1.pdf

Jackson, F. (1982). Epiphenomenal qualia. The Philosophical Quarterly, 127-136. https://doi.org/10.2307/ 2960077

James, W. [1902]. (1961). The varieties of religious experience. New York: Collier Books. 
Jarvis, M. (2005). The psychology of effective learning and teaching. Nelson Thornes.

Jarvis, P. (1992). Learning practical knowledge. New directions for adult and continuing education, (55), 89-95. https://doi.org/10.1002/ace.36719925511

Jennings, R. (2000). Participatory development as new paradigm: the transition of development professionalism. Prepared for the Community Based Reintegration and Rehabilitation in Post-Conflict Settings Conference, Washington DC.

Johnston, F. (2002). Tales of the unexpected: 'Most significant change' monitoring of the Brong Ahafo District Support Project (BADSP), Ghana November 2000 to December 2001. Unpublished report. Retrieved from http:/groups.yahoo.com/group/MostSignificantChanges

Kahn, R. (2008). From education for sustainable development to ecopedagogy: Sustaining capitalism or sustaining life. Green theory \& praxis: The journal of ecopedagogy, 4(1). https://doi.org/10.3903/gtp.2008.1.2

Kallis, G., Videira, N., Antunes, P., Pereira, Â. G., Spash, C. L., Coccossis, H., \& Santos, R. (2006). Participatory methods for water resources planning. Environment and Planning, 24(2), 215. https://doi.org/10.1068/ c04102s

Kanu, Y. (2011). Integrating Aboriginal perspectives into the school curriculum: Purposes, possibilities, and challenges. University of Toronto Press.

Kovan, J. T., \& Dirkx, J. M. (2003). "Being called awake": the role of transformative learning in the lives of environmental activists. Adult education quarterly, 53(2), 99-118. https://doi.org/10.1177/07417136022 38906

Kripke, S. (1971). Identity and necessity. Perspectives in the Philosophy of Language, 93-126.

Kucukaydin, I., \& Cranton, P. (2012). Participatory learning in formal adult education contexts. International Journal of Adult Vocational Education and Technology (IJAVET), 3(1), 1-12. https://doi.org/10.4018/javet. 2012010101

Lather, P. (2004). Critical inquiry in qualitative research: Feminist and poststructural perspectives: Science "after truth". Foundations for research: Methods of inquiry in education and the social sciences, 203-215.

Lave, J., \& Wenger, E. (1991). Situated learning: Legitimate peripheral participation. Cambridge, MA: Cambridge University Press. https://doi.org/10.1017/CBO9780511815355

Law Reform Commission of Canada. (2006). Retrieved from https://www.thecanadianencyclopedia.ca/en/article/ law-reform-commission-of-canada

Lew, J., \& Hardt, M. D. (2011). Controlling complexity: An introduction to question structure. SkillPlan.

Lewis, C. I. (1929). Mind and the world order. New York: Charles Scribner's Sons.

Lim, C. P., \& Chai, C. S. (2008). Teachers' pedagogical beliefs and their planning and conduct of computermediated classroom lessons. British Journal of Educational Technology, 39(5), 807-828. https://doi.org/ 10.1111/j.1467-8535.2007.00774.x

Lovett, T. (1983). A new initiative in community education. Peace by peace. Ulster People's College. Community Education Network.

Lunce, L. M. (2006). Simulations: Bringing the benefits of situated learning to the traditional classroom. Journal of Applied Educational Technology, 3(1), 37-45.

Lunch, C. (2008). Participatory video facilitation course. Oxford, UK. Retrieved from http://insightshare.org/ services/ourcourses

Lycan, W. G. (2001). The case for phenomenal externalism. Noûs, 35(s15), 17-35. https://doi.org/10.1111/00294624.35.s15.2

Mace, K. L., \& Bacon, C. E. W. (2019). The future of health professions education: considerations for competencybased education in athletic training. Athletic Training Education Journal, 14(3), 215-222. https://doi.org/ $10.4085 / 1403215$

Malley, D. F., Smith, M., \& Watts, P. D. (1992). Workshop report on 'life styles and sustainable development'. In Y. G. Lithman, R. R. Riewe, R. E. Wiest, \& R. E. Wrigley (Eds.), People and land in northern Manitoba (pp. 245-261). University of Manitoba Anthropology, 32.

Manitoba Bureau of Statistics. (2016). Retrieved from http://www.gov.mb.ca/mbs/ 
Manitoba Education Research Network [MERN]. (2017). Retrieved from http://www.mern.ca/index.asp

Manning, R., \& Harrison, N. (2018). Narratives of place and land: Teaching Indigenous histories in Australian and New Zealand teacher education. Australian Journal of Teacher Education, 43(9), 4. https://doi.org/ 10.14221/ajte.2018v43n9.4

Marshall, C., \& Rossman, G. B. (2014). Designing qualitative research. Sage publications.

Martin, N. (2014, February 22). College fails to make the grade. Winnipeg Free Press. Retrieved from http://www.winnipegfreepress.com/local/college-fails-to-make-the-grade-246651741.html

McDowell, J. H. (1998). Mind, value, and reality. Harvard University Press.

McLean, S. (2013). The whiteness of green: Racialization and environmental education. The Canadian Geographer/Le Géographe Canadien, 57(3), 354-362. https://doi.org/10.1111/cag.12025

Mercredi, O. (2009). Opasquia Times. The Pas, Manitoba.

Mercredi, O. (2010). Opasquia Times. The Pas, Manitoba.

Mertens, D. M. (2014). Research and evaluation in education and psychology: Integrating diversity with quantitative, qualitative, and mixed methods. Sage Publications.

Mezirow, J. (1990). How critical reflection triggers transformative learning. Fostering critical reflection in adulthood, 1-20.

Mezirow, J. (2000). Learning as transformation: Critical perspectives on a theory in progress. The Jossey-Bass Higher and Adult Education Series. Jossey-Bass Publishers, 350 Sansome Way, San Francisco, CA 94104.

Mezirow, J. (2009). An overview on transformative learning. Contemporary theories of learning, 90-105.

Michell, H., Tsannie Jr, J., \& Adam, A. (2018). Tu Pëhena-"Water is Life": Tracking Changes on Land, Lake, and River Systems in the Northern Saskatchewan Athabasca Region from the Perspectives of Denesuline Peoples. Green Theory and Praxis Journal, 11(1), 3-17.

Miller, R. B. (2001). Moderate modal realism. Philosophia, 28(1), 3-38. https://doi.org/10.1007/BF02379767

Moore, W. J. (1992). Schrödinger: life and thought. Cambridge University Press.

Moustakas, C. (1994). Phenomenological research methods. Sage Publications. https://doi.org/10.4135/ 9781412995658

Nagel, T. (1974). What is it like to be a bat? The Philosophical Review, 435-450. https://doi.org/10.2307/2183914

Newman, M. (2010). Calling transformative learning into question: Some mutinous thoughts. Adult Education Quarterly. https://doi.org/10.1177/0741713610392768

Nideffer, R. M. (2002). Getting Into The Optimal Performance State. Enhanced Performance Systems.

Nunnally, J. C., \& Bernstein, I. H. (1994). The general model and variance condensation. Psychometric Theory, 447-490.

Oakes, J., Muir, K., \& Joseph, R. (2000). Course taking and achievement in mathematics and science: Inequalities that endure and change. Fifth Annual National Institute of Science Education (NISE), Southfield, MI.

O'Sullivan, E., Morrell, A., \& O'Connor, M. A. (2002). Expanding the boundaries of transformative learning essays on theory and praxis. https://doi.org/10.1007/978-1-349-63550-4

Palmer, C. A. (1997). Environmental ethics. Australian Broadcasting Corporation.

Palmer, C. A. (2003). An overview of environmental ethics.

Phare, M. A. S. (2009). Denying the source: The crisis of First Nations water rights. Rocky Mountain Books Ltd.

Pinnegar, S., \& Daynes, J. G. (2006). Locating narrative inquiry historically: Thematics in the turn to narrative. In D. J. Clandinin (Ed.), Handbook of Narrative Inquiry (pp. 3-34). Thousand Oaks, CA: Sage Publications. https://doi.org/10.4135/9781452226552.n1

Pryor, J. H., Eagan, K., Blake, L. P., Hurtado, S., Berdan, J., \& Case, M. (2012). The American freshman: national norms fall 2012. Cooperative Institutional Research Program at the higher education research institute at UCLA.

Rasheed, R. A., Kamsin, A., \& Abdullah, N. A. (2020). Challenges in the online component of blended learning: A systematic review. Computers \& Education, 144, 103701. https://doi.org/10.1016/j.compedu.2019.103701 
Rey, J., \& Harrison, N. (2018). Sydney as an Indigenous place: "Goanna walking” brings people together. AlterNative: An International Journal of Indigenous Peoples, 14(1), 81-89. https://doi.org/10.1177/ 1177180117751930

Richardson, L. (1994). Writing: A method of inquiry. In N. Denzin, \& Y. Lincoln (Eds.), Handbook of Qualitative Research (pp. 516-529). London: Sage.

Rittel, H. W., \& Webber, M. M. (1973). Dilemmas in a general theory of planning. Policy sciences, 4(2), 155-169. https://doi.org/10.1007/BF01405730

Rooney, F. (2007, April 24). Josephine Mandamin and the Ashinabak Women's Water Commission. Section 15.ca. Rebels without a cause. Retrieved from http://section15.ca/features/people/2007/04/24/josephine_mandamin/

Rosenstein, B. (2008). Video use in social science research and program evaluation. International Journal of Qualitative Methods, 1(3), 22-43. https://doi.org/10.1177/160940690200100302

Roulston, K., \& Lewis, J. B. (2003). Learning to interview in the social sciences. Qualitative Inquiry, 9(4), 643668. https://doi.org/10.1177/1077800403252736

Russell, W. M. S., \& Burch, R. L. (1959). The principles of humane experimental technique. Methuen.

Ryle, G. (1938/1971). Categories. In Collected Papers, Volume II: Collected Essays. New York: Barnes and Noble.

Sandlin, J. A., Wright, R. R., \& Clark, C. (2011). Reexamining theories of adult learning and adult development through the lenses of public pedagogy. Adult Education Quarterly, 0741713611415836. https://doi.org/ $10.1177 / 0741713611415836$

Sharrock, W. W., \& Anderson, D. C. (1979). Directional hospital signs as sociological data. Information Design Journal, 1(2), 81-94. https://doi.org/10.1075/idj.1.2.02sha

Shaw, G., Brown, R., \& Bromiley, P. (1998, May-June). Strategic Stories. Harvard Business Review, 76, 41-50.

Shaw, R., Turvey, M. T., \& Mace, W. (1982). Ecological psychology: The consequence of a commitment to realism. In W. Weimer, \& D. Palermo (Eds.), Cognition and the symbolic process, 2 (pp. 159-226). Hillsdale, NJ: Lawrence Erlbaum Associates, Inc.

Simkin, M. G., \& Kuechler, W. L. (2005). Multiple-choice tests and student understanding: What is the connection?. Decision Sciences Journal of Innovative Education, 3(1), 73-98. https://doi.org/10.1111/j.15404609.2005.00053.x

Smart, J. C. (1976). Duties performed by department chairmen in Holland's model environments. Journal of Educational Psychology, 68(2), 194. https://doi.org/10.1037/0022-0663.68.2.194

Snowden, D. (1983). Eyes see; ears hear. A report to the President on Extension Service of Memorial University of Newfoundland, St. John's, Newfoundland.

Sorenson, E. R. (1975). Culture and the expression of emotion. Psychological anthropology, 361-372. https://doi.org/10.1515/9783110802818.361

Spearman, C. (1927). The abilities of man.

Spoon, J. (2014). Quantitative, qualitative, and collaborative methods: approaching indigenous ecological knowledge heterogeneity. Ecology and Society, 19(3). https://doi.org/10.5751/ES-06549-190333

Stepaniuk, J. R. (2019). Embedded Place-Responsive Learning, Participatory Video and Scholastic Achievement in Northern Manitoba Adult Environmental Education. Journal of Human Resource and Sustainability Studies, 7(2), 191-232. https://doi.org/10.4236/jhrss.2019.72013

Stewart, S., Riecken, T., Scott, T., Tanaka, M., \& Riecken, J. (2008). Expanding health literacy: Indigenous youth creating videos. Journal of Health Psychology, 13(2), 180-189. https://doi.org/10.1177/1359105307086709

Strauss, A. L., \& Corbin, J. M. (1990). Basics of qualitative research (Vol. 15). Newbury Park, CA: Sage.

Sutherland, D., \& Henning, D. (2009). Ininiwi-Kiskānītamowin: A framework for long-term science education. Canadian Journal of Science, Mathematics and Technology Education, 9(3), 173-190. https://doi.org/ $10.1080 / 14926150903118359$

UCN. (2020/2025). Strategic and Academic plans. University College of the North, Manitoba.

Van den Noortgaete, F. (2015). Relating to nature: Motivation, hermeneutics and spirituality.

Van Manen, M. (1990). Researching lived experience: Human science for an action sensitive pedagogy. Suny 
Press.

Vygotsky, L. S. (1978). Mind in society. Cambridge, MA: Harvard University Press.

Walter, P. (2011). Dead wolves, dead birds, and dead trees: Catalysts for transformative learning in the making of Scientist-Environmentalists. Adult Education Quarterly, 63(1), 24-42. https://doi.org/10.1177/0741713611 426348

Walter, P. (2013, June). Experiential and transformative learning in community-based ecotourism. In Annual Conference (pp. 620).

Widdowson, F., \& Howard, A. (2009). Disrobing the Aboriginal industry: The deception behind indigenous cultural preservation. Montreal, QC: McGill-Queens University Press.

Williams, R. M. (1967). Individual and group values. The Annals of the American Academy of Political and Social Science, 371(1), 20-37. https://doi.org/10.1177/000271626737100102

Williamson, J. (1978). Decoding advertisements: ideology and meaning in advertising. Marion Boyers.

Wilson, S. (2008). Research is ceremony: Indigenous research methods. Fernwood Publishing. Halifax and Winnipeg.

Wilson, S. S. (2004). Research as ceremony: Articulating an Indigenous research paradigm (Doctoral dissertation, Monash University).

Woolfolk, A. (2005). Educational psychology (9th ed.). (Active Learning Edition). Boston: Pearson/Allyn \& Bacon.

Wright, R. R., \& Sandlin, J. A. (2009). Popular culture, public pedagogy and perspective transformation: The Avengers and adult learning in living rooms. International Journal of Lifelong Education, 28(4), 533-551. https://doi.org/10.1080/02601370903031389

Wyart, V., \& Tallon-Baudry, C. (2009). How ongoing fluctuations in human visual cortex predict perceptual awareness: baseline shift versus decision bias. The Journal of neuroscience, 29(27), 8715-8725. https://doi.org/10.1523/JNEUROSCI.0962-09.2009

Yarbrough, J. R. (2018). Adapting Adult Learning Theory to Support Innovative, Advanced, Online Learning-WVMD Model. Research in Higher Education Journal, 35.

Zinsser, W. (2006). On writing well: The classic guide to writing nonfiction. New York, NY.

\section{Copyrights}

Copyright for this article is retained by the author(s), with first publication rights granted to the journal.

This is an open-access article distributed under the terms and conditions of the Creative Commons Attribution license (http://creativecommons.org/licenses/by/4.0/). 